\title{
The Art of Coupon Tests
}

\author{
Yuner Huang and Ben Young* \\ Department of Civil Engineering, The University of Hong Kong, Pokfulam Road, Hong Kong, China
}

\begin{abstract}
Tensile coupon tests are commonly carried out to determine the material properties of metallic materials in research and industry. However, ambiguities are found in the current specifications in determining initial Young's modulus of material, which may lead to different test results. The material properties lay the crucial foundation in research and structural design. Different researchers may interpret coupon test results differently. Therefore, standard procedures of coupon test and the interpretation of test results are important and worth investigating. In this study, a series of tensile coupon tests on metallic materials, such as cold-formed carbon steel, cold-formed stainless steel and aluminium alloy, were carried out using different test and data analysis procedures. Two types of stainless steel material, namely lean duplex and ferritic, were investigated. The test and data analysis procedures of loading rate on coupon specimens, determination of cross-sectional area of curved coupons and Young's modulus were carefully designed. In this study, tensile coupon test and data analysis procedures are proposed for both flat and curved coupons. The proposed procedures are able to eliminate possible errors and provide clear guidelines for tensile coupon tests.
\end{abstract}

Keywords: Aluminium alloy; Cold-formed steel; Ferritic; Lean Duplex; Material properties; Metallic material; Stainless steel; Tensile coupon tests; Test procedure

\footnotetext{
* Corresponding author. Tel.: +852-2859-2674; fax: +852-2559-5337.

E-mail address: young@hku.hk (B. Young).
} 


\section{Introduction}

Metallic materials are commonly used in structural projects, due to the high strength-toweight ratio, high degree of recyclability and ease of construction comparing with other constructional materials. Determination of material properties for metallic materials, especially the initial Young's Modulus, yield strength, ultimate strength and strains, lays a solid foundation in structural design and research. Therefore, tensile coupon tests as the most commonly used experimental method to obtain material properties are widely known and frequently carried out by engineers and researchers. Specifications on tensile testing method for metallic materials are also available to facilitate engineers and researchers to obtain material properties. However, it should be noted that inconsistent coupon test procedure and data analysis leads to inaccurate results. Therefore, it is worth investigating tensile coupon tests in order to propose a standard and user-friendly procedure for test and data interpretation.

Previous investigations [1-6] have found that stress increases with loading rate for various metallic materials, and thus determination of yield strength and ultimate strength are sensitive to the loading rate during testing. The Australian Standard (AS) [7], European Code (BSI) [8] and American Specification (ASTM) [9] specify a range of loading rate for tensile coupon tests. However, the lower bound and upper bound of the loading rate provide quite different results in terms of the yield strength and ultimate strength. Krempl and Khan [5] indicated that the stress drops and maintains at the equilibrium boundary (static curve) by holding the strain for a very long time during testing, and the static stress-strain curve can be obtained under a vanishing loading rate. However, it is not practical to hold the strain for such a long time or use a vanishing loading rate. In addition, it is also observed by Krempl and Khan [5] that the stress drops diminishing with time. Therefore, coupon tests were conducted by holding the strain for 1-2 minutes during testing for the purpose of obtaining the static stressstrain curves [10-12]. The Guide to Stability Design Criteria for Metal Structures [13] suggested hold the strain for at most 5 minutes, so as to eliminate the effect of loading rate and obtain static material properties. Therefore, coupon test procedure and loading rate are ambiguous, which may lead to an inconsistent test results.

Curved coupon specimens obtained from corners of cold-formed sections were conducted by many researchers $[10,14-16]$ to investigate the strength enhancement due to cold-forming 
process. However, it is difficult to measure the cross-sectional area accurately or apply uniform tensile stress to coupon specimen during testing, because of the curved geometry of the specimen. Current specifications [7-9, 17] provide limited guidance to determine the cross-sectional area of curved coupons. Therefore, researchers [10, 14-16] used different methods for coupon tests on curved specimens, which may lead to different test results.

The initial Young's modulus is considered as one of the most important material properties. It also affects the accuracy in determining the $0.2 \%$ proof stress $\left(\sigma_{0.2}\right)$. However, the current specifications [7-9, 17] recommended different methods to obtain the Young's modulus. It is expected that different values of initial Young's modulus are obtained using different methods, which may eventually influence the coupon test results. Thus, there is an eminent need to compare these methods in terms of accuracy and simplicity, and recommend clear guidelines for tensile coupon tests.

In this study, tensile coupon tests using different test and data analysis procedures were conducted. The procedures of coupon tests were carefully designed. The test specimens in this study include cold-formed carbon steel grade G450, cold-formed lean duplex stainless steel (EN 1.4162), cold-formed ferritic stainless steel (EN 1.4003) and aluminium T6 alloy. The cold-formed carbon steel and aluminium alloy are widely used in construction, while cold-formed lean duplex stainless steel is a relatively new material that is gaining popularity in construction industry. A relatively convenient procedure for tensile coupon tests is recommended.

\section{Experimental Investigation}

\subsection{Test specimens}

A total of 48 tensile coupon tests of cold-formed carbon steel (G450), cold-formed lean duplex stainless steel (EN 1.4162), cold-formed ferritic stainless steel (EN 1.4003) and aluminium T6 alloy was carried out. The cross-sectional dimensions of the flat and curved coupon specimens were measured. The nominal dimensions of the coupon specimens are shown in Fig. 1. The cross-sectional dimensions of the curved coupon specimens are 
summarized in Table 1 with the definition of symbols shown in Fig. 2. The coupon specimens are labeled such that the material, shape of the coupon and the loading rate could be identified, as shown in Tables 1 and 2. The first letter represents the metallic material. The letters G, L, F and A represent cold-formed steel G450, lean duplex stainless steel, ferritic stainless steel and aluminium alloy, respectively. The second letter indicates the shape of the coupon, such as "F" and "C" representing flat and curved coupons, respectively. The letter right after the hyphen represents the loading rate applied on the specimen during testing. There are four series of loading rate, namely slow (S), research (R), lower-bound (L) and upper-bound (U), representing the slow loading rate, the loading rate recommended for research purpose, the lower-bound and upper-bound of loading rates recommended by the ASTM specification [9], respectively. The loading rates for each series and material are summarized in Table 2 and detailed in Section 2.3 of this paper. Two or three coupon tests were carried out for each series, and thus the loading rates in Table 2 are the average value measured from the coupon tests in each series. The number shown in the specimen label after the loading rate series represents the number of tests in each series, as shown in Tables $3-6$. For example, the specimen “AF-R2” represents the aluminium alloy (A) flat coupon (F) tested under the loading rate recommended for research purpose (R) for the second coupon test. The zinc coating on coupon surfaces of the cold-formed carbon steel was removed using hydrochloric acid prior to measuring the cross-sectional dimensions, except for specimens GF-R1-zinc, GF-R2-zinc and GF-R3-zinc with the coating remain throughout the test for comparison purpose. The MTS tensile loading machine of $50 \mathrm{kN}$ capacity was used for the tensile coupon tests, except that the specimens LF-R1-Instron and LF-R1-MTS250 were tested using tensile loading machines of Instron $50 \mathrm{kN}$ capacity and MTS $250 \mathrm{kN}$ capacity, respectively.

The flat coupon specimens of cold-formed steel G450 (G) were extracted from steel sheet, while the curved coupon specimens GC-R1 and GC-R2 were extracted from the two corners of a cold-formed steel channel section with nominal cross-sectional dimension $(D \times B \times t)$ of $136 \times 52 \times 1.9 \mathrm{~mm}$, where $D$ is the depth of the web, $B$ is the width of the flange, and $t$ is the plate thickness. Flat and curved coupon specimens of cold-formed lean duplex stainless steel (L) were extracted from the flat portion and corners of a cold-formed lean duplex stainless steel rectangular hollow section (RHS) with nominal cross-sectional dimension $(D \times B \times t)$ of $100 \times 50 \times 2.5 \mathrm{~mm}$. Flat coupon specimens of cold-formed ferritic stainless steel (F) were extracted from the flat portion of a cold-formed ferritic stainless steel rectangular hollow 
section (RHS) with nominal cross-sectional dimension $(D \times B \times t)$ of $100 \times 50 \times 3 \mathrm{~mm}$. Flat coupon specimens of aluminium alloy (A) were extracted from the web of a plain channel section with nominal cross-sectional dimension $(D \times B \times t)$ of $86 \times 50 \times 2 \mathrm{~mm}$.

The dimensions of flat coupons conformed to the Australian Standard AS 1391-2007 [7], British Standard BS EN ISO 6892-1 [8] and American Specification ASTM E8/E8M-13 [9], as shown in Fig. 1. Dimension of each specimen was measured prior to testing. For the flat coupon specimens, the Vernier digital caliper was used to measure the thickness $(t)$ and width $(B)$ of the rectangular cross-section at the mid-length of the specimen. For the curved coupon specimens, the width $(B)$, overall height $(H)$ and heights at the two edges $\left(t_{1}, t_{2}\right)$ were measured using the Mitutoyo digital micrometer with flat spindle, thickness between midpoints of outer and inner curved surfaces $\left(t_{0}\right)$ was measured by the Mitutoyo digital micrometer with point spindle, the outer radius $\left(r_{o}\right)$ and inner radius $\left(r_{i}\right)$ were measured using Moore \& Wright radius gauges. The measured dimensions and the cross-sectional areas of curved specimens are shown in Table 1. Fig. 2 shows the definition of symbols for the crosssectional dimensions of curved coupon specimens. The cross-sectional areas of the curved coupon specimens $A_{w}, A_{c}$ and $A_{g}$ in Table 1 were obtained from three different methods, namely (i) weight and density method, (ii) AutoCAD method, and (iii) geometrical equations, respectively. These methods are described in Section 3.4 of this paper.

\subsection{Test set-up}

The MTS tensile testing machine with capacity of $50 \mathrm{kN}$ and Teststar IIs controller were used to conduct the tensile coupon tests, except for specimens LF-R1-MTS250 and LF-R1-Instron. The specimen LF-R1-MTS250 was tested by MTS tensile testing machine with capacity of $250 \mathrm{kN}$ and Flex Test SE controller, while the specimen LF-R1-Instron was tested by Instron 4469 table-tap load frame with capacity of $50 \mathrm{kN}$. The MTS tensile testing machine of $50 \mathrm{kN}$ capacity and $250 \mathrm{kN}$ capacity as well as the Instron tensile machine are shown in Fig. 3. Tensile loading was applied to the flat coupons by gripping both ends with a pair of flat surface clamps, as shown in Fig. 3(a), (c) and (d). The curved coupons cannot be gripped by flat surface clamps due to its curved surface, and thus two holes were drilled at a distance of $21 \mathrm{~mm}$ from both ends of the coupons, as shown in Fig. 1(b). The tensile force was applied by two pins through the holes, which is in line with the centroid of the cross-section in order to avoid bending stress in the coupons, as shown in Fig. 3(b). It is stated in the BSI [8] and 
ASTM [9] that the ends of the curved coupon specimens may be flattened for gripping in the testing machine. However, the method of flattening the curved surfaces at the two ends of the coupons introduced eccentricity and caused additional bending, especially for curved coupons with small radius. Therefore, it is not correct to flatten the ends of the curved coupons. Any possible bending stress on the curved coupons should be avoided, such as by loading through two pins.

Extensometers and strain gauges were used to measure the longitudinal tensile strain of the coupon specimens. MTS extensometer of $50 \mathrm{~mm}$ gauge length was used for the flat coupon specimens with three-point contact knife edges, except that Instron extensometer of $50 \mathrm{~mm}$ gauge length was used for flat coupon LF-R1-Instron. MTS extensometer of $25 \mathrm{~mm}$ gauge length was used for the curved coupon specimens with standard knife edges. Comparing with the readings obtained from the extensometers, the strain gauge readings are more accurate, but for a much smaller range. Two linear TML strain gauges were attached at mid-length to the centre of both faces of each coupon using TML strain gauge adhesive of CN series to measure the strains in the initial part of the stress-strain curve. The important material property, initial Young's modulus $\left(E_{o}\right)$, was determined by the readings obtained from strain gauges. For the tests conducted using MTS tensile testing machine with capacity of $50 \mathrm{kN}$, a linear variable displacement transducer (LVDT) was attached at the upper grip and pointed at the lower grip of the testing machine, so as to measure the relative displacement between the two grips. The coupon test set-ups are shown in Fig. 3.

\subsection{Test procedures}

The loading machine was driven by displacement control of stroke during the tensile coupon tests. The loading process is divided into 4 stages; $(1)$ elastic range (before $\sigma_{p}$ ) from beginning to proportional limit $\left(\sigma_{p}\right)$; (2) yielding range ( $\sigma_{p}$ to $\sigma_{y}$ ) from proportional limit to yield strength $\left(\sigma_{y}\right)$; (3) strain hardening range $\left(\sigma_{y}\right.$ to $\sigma_{u}$ ) from yield strength to ultimate strength $\left(\sigma_{u}\right)$; and (4) post ultimate range ( $\sigma_{u}$ to fracture). A lower loading rate was applied in the elastic range than other ranges to ensure sufficient number of data in determining the initial Young's modulus. It should be noted that the Young's modulus is an important material property, which has a direct influence in determining the yield strength $\left(\sigma_{y}\right)$ and Ramberg-Osgood parameter $(n)$. Most of the strain occurs after proportional limit for metallic 
materials. Thus, a higher loading rate was applied beyond the elastic range to avoid long testing time. The loading rates applied during testing are categorized into four series, such as slow (S), research (R), lower-bound (L) and upper-bound (U). The slow loading rate (S) and the recommended loading rate for research purpose $(\mathrm{R})$ are designed to complete a tensile coupon test for around 60 and 30 minutes, respectively. The average strain rate at each loading stage was measured for each specimen in order to investigate the effect of strain rate. The average values of the strain rates for each series are summarized in Table 2. It should be noted that the measured loading rates of the specimens in the same series are quite close to each other, with the maximum difference of $6.1 \%$ and average of $2.0 \%$. The strain rates specified in the AS [7], BSI [8] and ASTM [9] are also summarized in Table 2. According to the lower bound of the strain rates specified in the current ASTM specification, it takes around 3 minutes to complete the tensile coupon test for aluminium alloy with strain at fracture of around 9\%, while it takes less than 10 minutes to complete a tensile coupon test for cold-formed lean duplex stainless steel flat coupon with strain at fracture of around $40 \%$. Despite the fact that the ASTM [9] specified the lower bound of the strain rates, such strain rates are considered to be very fast in the laboratory for research purpose.

Straining was held for 5 minutes at critical locations to obtain the static drops. The $1^{\text {st }}$ static drop was obtained right after the proportional limit $\left(\sigma_{p}\right)$, and the $2^{\text {nd }}$ static drop was obtained near the yield strength $\left(\sigma_{y}\right)$, so that the static yield strength can be determined. For metallic material that has no yield plateau in the stress-strain curve, the yield strength was determined as the $0.2 \%$ proof stress $\left(\sigma_{0.2}\right)$. The $3^{\text {rd }}$ static drop was obtained near the ultimate strength $\left(\sigma_{u}\right)$. It is observed that the stress reduces slowly during the holding of strain for 5 minutes in all of the three materials investigated in this study. Such behaviour is called stress relaxation. A typical static drop due to stress relaxation is shown in Fig. 4. An overshoot of stress was found when the strain rate increased to $0.03 / \mathrm{min}$ after the static drop, as shown in Fig. 4.

In order to compare the unloading-reloading method in the BSI [8] Specification with other methods to determine the initial Young's modulus, the unloading-reloading process was also performed. When the load was applied right after the proportional limit $\left(\sigma_{p}\right)$, the stress was released to around $15 \%$ of the force prior to unloading, and then re-loaded to the original stress level using the same loading rate. Displacement control was used in the unloadingreloading process. The determination of the Young's modulus using the unloading-reloading 
method is detailed in Section 3.4 of this paper. The loading history of the specimen AF-R3 with unloading-reloading process is demonstrated in Fig. 5.

\section{Test results}

\subsection{Dynamic and static material properties}

Dynamic stress-strain curves of the coupon specimens at different loading rates were plotted, as shown in Figs 6 - 11. The coupon test procedure to obtain the dynamic curves is explained in steps A5-1 to A5-5 of the Procedure A for flat coupons, and step B5 of the Procedure B for curved coupons in Section 4 of this paper. The material properties obtained from the dynamic curves are summarized in Tables $3-6$. It is shown that the stress increases with strain rate. The static material properties were obtained from the static stress-strain curves. The test procedure to obtain the static material properties are described in steps A5-6 to A5-8 of the Procedure A for flat coupons, and step B5 of the Procedure B for curved coupons in Section 4 of this paper. The static material properties are summarized in Tables 7 - 11, including initial Young's modulus $(E)$, stress at proportional limit $\left(\sigma_{p}\right)$, strain corresponding to the proportional limit $\left(\varepsilon_{p}\right), 0.2 \%$ proof stress $\left(\sigma_{0.2}\right)$, strain at $0.2 \%$ proof stress $\left(\varepsilon_{0.2}\right)$, ultimate strength $\left(\sigma_{u}\right)$, ultimate strain $\left(\varepsilon_{u}\right)$, strain at fracture $\left(\varepsilon_{f}\right)$ and Ramberg-Osgood parameter $(n)$. It is shown that the static material properties obtained from the coupon specimens tested at different strain rates generally provide similar static values. The mean values and COV of the static material properties obtained at different loading rates were also calculated, as shown in Tables $7-11$. It should be noted that the dynamic $0.2 \%$ proof stress $\left(\sigma_{0.2}\right)$ at the upper-bound loading rate is $7.6 \%, 9.1 \%, 5.9 \%$ and $5.2 \%$ higher than the average static $0.2 \%$ proof stress for cold-formed steel G450, lean duplex stainless steel, ferritic stainless steel and aluminium alloy, respectively. The dynamic ultimate strength $\left(\sigma_{u}\right)$ is $8.8 \%, 13.1 \%, 11.0 \%$ and $10.5 \%$ higher than the static ultimate strength for the four materials, respectively. Therefore, the existing ASTM [9] Specification leads to an unconservative prediction for the material strengths up to $13.1 \%$. In addition, the static curves in the loading rate series for research purpose (R) and lower-bound in specification (L) are plotted for the four materials as shown in Figs 6 - 9. It is shown that the static curves obtained from coupon tests using different 
loading rates are close to each other, which means that the test results of the static curves are similar for different loading rates.

\subsection{Static drops}

It is found from the literature that the stress of metallic materials reduce when the strain is held at a constant value for a period of time, and such behaviour is called "stress relaxation". In this study, straining of the coupons were held at critical locations during the loading process for 5 minutes (300 seconds), in order to investigate the stress relaxation behaviour and propose a test procedure to obtain an accurate static material properties in a reasonable period of time. In this study, the typical locations of static drops in a stress-strain curve are shown in Fig. 12. The reductions of stress during the stress relaxation were recorded. The average stress reductions for 60, 100 and 300 seconds of specimens in each loading rate series are calculated, as shown in Tables $12-15$, in which the stress reductions $\left(\Delta_{s, t} / \sigma_{o}\right)$ are equal to the ratio of stress reduced (stress drop) for a specified period of time $\left(\Delta_{s, t}\right)$ over the stress prior to static drop $\left(\sigma_{o}\right)$. The stress reductions of the coupon specimens in the same series are quite similar, with the maximum discrepancy of $8 \%$ compared with the average values in the same series. The stress relaxation for specimens GF-R1-zinc, LF-R1, FF-S1 and AF-R1 are plotted in 10 seconds interval, as shown in Figs 13 - 16, respectively. The preceding strain rate in Figs $13-16$ is defined as the strain rate prior to the stress relaxation.

It is observed from the test results that, firstly, the stress reduced by around 5 - $8 \%$ at yield strength and ultimate strength during the stress relaxation. It is also found that the stainless steel materials have a relatively larger amount of stress reduction compared to the coldformed carbon steel (G450) and aluminium T6 alloy under the same period of time for stress relaxation. Secondly, the stress reduced rapidly for the first 60 seconds, then the stress reduced slowly in a diminishing rate. The stress further reduced for less than $1.5 \%$ between 100 and 300 seconds. Thirdly, as the strain rate increases the amount of stress reduction also increases. As mentioned earlier in the paper, the dynamic material properties increase with the strain rate. Thus, a larger static drop takes place to bring the stress to the static curve. Finally, the stress reduction at yield strength and ultimate strength under the same preceding strain rate are similar for cold-formed carbon steel (G450) and cold-formed stainless steel, as shown in Tables 12 - 15 and Figs 13 - 16. However, the stress reduction at ultimate strength 
is much higher than that at yield strength under the same preceding strain rate for the aluminium T6 alloy, as shown in Table 15 and Fig. 16. Therefore, it is suggested that:

(i) Stress relaxation should be performed during tensile coupon tests, and the static material properties should be obtained and used. Otherwise, the yield strength and ultimate strength may be overestimated by as much as $10 \%$.

(ii) It is recommended to pause the straining for 100 seconds to obtain the static drop. However, if efficiency is required for the coupon tests, pausing for 60 seconds gives similar yield strength and ultimate strength with less than $1 \%$ difference compared with those pausing for 100 seconds.

\subsection{Initial Young's Modulus}

Initial Young's Modulus $(E)$ is an important material property for calculating design strengths and finite element analysis. Determination of the initial Young's modulus accurately is important, especially for materials with rounded stress-strain curves. This is due to the fact that the determination of $0.2 \%$ proof stress depends on the initial Young's modulus. Hence, if the initial Young's modulus is inaccurately determined, subsequently the value of $0.2 \%$ proof stress is also inaccurate. The current AS [7], BSI [8], ASTM [9] and EN ISO [17] specifications recommended three different methods to determine the Young's Modulus, and these methods are follows: (i) slope of linear portion [7-9], (ii) average slope of the unloading-reloading curve [8], and (iii) slope between two specified points calculated using Eq. (1) [17],

$$
E=\frac{\sigma_{2}-\sigma_{1}}{\varepsilon_{2}-\varepsilon_{1}}
$$

where $\sigma_{1}$ is the stress measured at the strain $\varepsilon_{1}=0.0005$, and $\sigma_{2}$ is the stress measured at the strain $\varepsilon_{2}=0.0025$. In addition, the BSI [8] and ASTM [9] specifications recommend using extensometer to obtain the strains of coupon specimens during testing, while the EN ISO 527-1 [17] specification and some researchers [10,18] use strain gauges for a more accurate measurement of initial Young's modulus. Therefore, the initial Young's modulus obtained from the three methods using both strain gauges and extensometer are compared in this study. The Young's modulus obtained from strain gauges and extensometer readings for specimen 
LF-L1 are plotted in Fig. 17. The Young's modulus obtained from the three methods using both strain gauges and extensometer for different coupon specimens are summarized in Table 16.

For the slope of linear portion ( $1^{\text {st }}$ method) in the elastic range of the stress-strain curve, the ASTM [9] specifications do not provide guidance to determine the linear portion, while BSI [8] recommends the lower limit ( $10 \%$ of $\sigma_{0.2}$ ) and upper limit (50\% of $\sigma_{0.2}$ ) to determine the slope of the linear portion. In this study, the nominal $0.2 \%$ proof stresses $\left(\sigma_{0.2}\right)$ of the coldformed carbon steel (G450), cold-formed lean duplex stainless steel, cold-formed ferritic stainless steel and aluminium T6 alloy are equal to 450, 450, 280 and $250 \mathrm{MPa}$, respectively. According to the experimental results, it is recommended that the following stress intervals to be used in the linear portion for the determination of initial Young's modulus: (a) $20-45 \%$ of nominal $0.2 \%$ proof stress for cold-formed carbon steel (G450), cold-formed lean duplex and ferritic stainless steel flat coupons, (b) 25 - 35\% of nominal $0.2 \%$ proof stress for aluminium T6 alloy, and (c) 45 - 65\% of nominal 0.2\% proof stress for cold-formed carbon steel (G450) and cold-formed lean duplex stainless steel curved coupons. It should be noted that the suggested stress interval (45 - 65\% of nominal $\sigma_{0.2}$ ) for cold-formed carbon and stainless steel curved coupons in this study exceeds the upper limit (50\% of $\sigma_{0.2}$ ) that recommended by BSI [8], due to the strength enhancement by cold-working in the curved coupon. It should also be noted that the lower limit of the stress intervals in the linear portion started at 20, 25 and $45 \%$ of the nominal $0.2 \%$ proof stresses for the three different types of specimens, and this is due to the initial curvature of the coupon specimens that caused inaccuracy in the initial part of the stress-strain curves. The initial Young's modulus obtained by the $1^{\text {st }}$ method for different materials is shown in Tables $3-11$ and 16 , while those obtained by the unloading-reloading method $\left(2^{\text {nd }}\right.$ method $)$ and the slope between two specific points ( $3^{\text {rd }}$ method) were summarized in Table 16.

It is observed that the initial Young's modulus measured by extensometer is similar to that using strain gauges for flat coupons of cold-formed carbon steel (G450) and aluminium T6 alloy. However, the initial Young's modulus measured by extensometer is not as accurate as those using strain gauges for cold-formed carbon steel (G450) curved coupons as well as cold-formed stainless steel flat and curved coupons, as shown in Table 16. The cold-formed carbon steel (G450) curved coupons as well as the cold-formed stainless steel flat and curved 
coupons were extracted from sections undergoing cold-working, which include certain amount of residual stresses in the sections during the cold-forming process. Therefore, initial curvature was found in longitudinal direction of the coupon specimens, and thus the strains measured from the two sides of the coupon specimens were different. Such strain difference caused by the initial curvatures can be compensated by averaging the strains measured from the two sides, as shown in Fig. 18.

For the strain gauge measurement, it is observed that the slope of linear portion $\left(1^{\text {st }}\right.$ method) gives the largest value, while the slope between two points ( $3^{\text {rd }}$ method) gives the smallest value of the initial Young's modulus. On average, the initial Young's modulus obtained by the $2^{\text {nd }}$ method and the $3^{\text {rd }}$ method are $2.6 \%$ and $15.3 \%$ smaller than those obtained by the $1^{\text {st }}$ method for all specimens, as shown in Table 16. For cold-formed steel (G450) and ferritic stainless steel with large value of Ramberg-Osgood parameter ( $n$ ), the Young's modulus obtained by the $3^{\text {rd }}$ method is $13.6 \%$ and $33.4 \%$ smaller than those obtained by the $1^{\text {st }}$ method, respectively. It is because the strain $\varepsilon_{2}=0.0025$ falls well beyond the proportional limit $\left(\sigma_{p}\right)$, and thus leads to a gentler slope than the linear portion of the elastic range. The $2^{\text {nd }}$ method requires unloading-reloading process during testing, which is not easy to operate at high strain rates. Furthermore, the data analysis of the $1^{\text {st }}$ method is more straightforward compared to the $2^{\text {nd }}$ method. Therefore, the following suggestions on determination of Young's Modulus are proposed:

(i) For coupon specimen that is extracted from cold-formed sections, it is recommended to obtain strains from both sides of the coupon specimens (e.g. use strain gauges on both sides), and the Young's modulus should be obtained using the average strains from both sides.

(ii) For coupon specimen that is not cold-formed (e.g. steel sheet), strain measurements at both sides of the coupon is optional.

(iii) It is recommended to obtain the Young's modulus by the slope of linear portion $\left(1^{\text {st }}\right.$ method). The detail procedure is shown in steps A5-1 and A5-2 of the Procedure A for flat coupons, and step B5 of the Procedure B for curved coupons in Section 4 of this paper. 


\subsection{Cross-sectional Area of Curved Coupons}

It is well known that the strengths of the curved portions in cold-formed sections can be considerably increased compared to the strengths at the flat portions, due to the cold-forming process. Thus, the material properties of curved portions of sections, such as corner coupons, are also important and corner coupon tests were conducted [10, 14-16]. However, it is not easy to measure the unsymmetrical cross-sectional area of curved coupons accurately. In this study, three methods are used to determine the cross-sectional area of the curved coupons, namely (i) weight and density method, (ii) AutoCAD method, and (iii) Geometrical equations.

In the weight and density method ( $1^{\text {st }}$ method), the cross-sectional area equals to the mass of the specimen divided by the length and then also divided by the density of the material as stated in Clause 7.2.2.2 of ASTM Standard [9]. Therefore, the following procedure is used in this study: (1) Two lines were marked on the curved coupon specimen to indicate the gauge length of $25 \mathrm{~mm}$ prior to testing; (2) After testing, the specimen was cut along the marked lines, and the portion between the gauge length was obtained; (3) Clean the surfaces of the cut portion between the gauge length and weigh the cut portion; (4) the cross-sectional area was determined as the weight divided by $25 \mathrm{~mm}$ and further divided by the density of the material, as shown in Fig. 19. For the AutoCAD method $\left(2^{\text {nd }}\right.$ method), the geometry of the cross-section area of curved coupon is drawn using the commercial software AutoCAD [19] with the measured dimensions as shown in Table 1. A typical geometry drawn by AutoCAD is shown in Fig. 2. In AutoCAD, the cross-sectional area was determined by the property function of geometry. For the geometrical equations method ( $3^{\text {rd }}$ method), the cross-section of the curved coupon is divided into 4 parts $\left(A_{1}, A_{2}, A_{3}\right.$ and $\left.A_{4}\right)$, as shown in Fig. 20(a). The area of each part can be calculated using geometric Eqs (2) - (5) as follows,

$$
\begin{aligned}
& A_{1}=r_{o}^{2}\left(\sin ^{-1} \frac{B}{2 r_{o}}\right)-\frac{B}{2} \sqrt{r_{o}^{2}-\left(\frac{B}{2}\right)^{2}} \\
& A_{2}=B\left\{t_{o}-\left[r_{o}-\sqrt{r_{o}^{2}-\left(\frac{B}{2}\right)^{2}}\right]\right\}
\end{aligned}
$$




$$
\begin{aligned}
& A_{3}=x B\left\{\frac{t_{1}+t_{2}}{2}-t_{o}+\left[r_{o}-\sqrt{r_{o}^{2}-\left(\frac{B}{2}\right)^{2}}\right]\right\} \\
& A_{4}=r_{i}\left(\frac{B-2 x}{2}-r_{i} \tan ^{-1} \frac{B-2 x}{2 r_{i}}\right)
\end{aligned}
$$

where the definition of symbols for these equations are shown in Fig. 20(b). The crosssectional area of the curved coupons $A_{g}=A_{1}+A_{2}+2 A_{3}+2 A_{4}$. Therefore, the cross-sectional area can be calculated using Eqs (6) - (7), with the measured dimensions as shown in Table 1.

$$
\begin{aligned}
& A_{g}=r_{o}^{2}\left(\sin ^{-1} \frac{B}{2 r_{o}}\right)+\frac{B}{2}\left[(1-4 x) \sqrt{r_{o}^{2}-\left(\frac{B}{2}\right)^{2}}+(2-4 x)\left(t_{o}-r_{o}\right)+2 x\left(t_{1}+t_{2}\right)\right]+r_{i}\left(B-2 x-2 r_{i} \tan ^{-1} \frac{B-2 x}{2 r_{i}}\right) \\
& \text { where } x=\frac{-B\left(2 a-r_{i}\right)+r_{i} \sqrt{B^{2}-16 a r_{i}+16 a^{2}}}{\left.4\left(r_{i}-a\right)\right)} ; a=\frac{t_{1}+t_{2}}{2}-t_{o}+\left[r_{o}-\sqrt{r_{o}^{2}-\left(\frac{B}{2}\right)^{2}}\right]
\end{aligned}
$$

The cross-sectional area of the four curved coupons GC-R1, GC-R2, LC-R1 and LC-R2 obtained by the three methods are summarized in Table 1 , where $A_{w}, A_{c}, A_{g}$ are the crosssectional areas determined using the weight and density method ( $1^{\text {st }}$ method), AutoCAD method ( $2^{\text {nd }}$ method), and geometrical equations method ( $3^{\text {rd }}$ method), respectively. Theoretically, the three methods should give a similar cross-sectional area. However, the weight and density method ( $1^{\text {st }}$ method) gives the average of $4.9 \%$ and $5.3 \%$ different values from the AutoCAD method ( $2^{\text {nd }}$ method) and geometrical equations method ( $3^{\text {rd }}$ method) for the four coupon specimens. Such results are probably due to the gauge length of the coupon specimen between the marked lines was not easy to be cut accurately. The AutoCAD method ( $2^{\text {nd }}$ method) and geometrical equations method ( $3^{\text {rd }}$ method) give quite similar values, with the differences ranged from $0.1 \%$ to $1.9 \%$ for the four specimens. Considering the accuracy of the measurement, the AutoCAD method ( $2^{\text {nd }}$ method) and the geometrical equations method ( $3^{\text {rd }}$ method) are recommended for the determination of the cross-sectional area of curved coupons. It should be noted that the geometric equations to calculate the crosssectional areas of the curved coupons in the existing specifications [7-9] can only be used for coupons extracted from tubes, and thus they are not suitable for curved specimens extracted from the corners of thin-walled rectangular hollow sections or open sections with $2 r_{i}<B$, where $r_{i}$ and $B$ are the inner radius and gauge width of the curved coupon, as shown in Fig. 2 
and Fig. 20(b). The geometrical equations method ( $3^{\text {rd }}$ method) proposed in this paper is suitable for curved specimens with $2 r_{i}<B$, as shown in Eqs (2) - (7).

\subsection{Zinc coating and loading devices}

Tensile coupon tests on cold-formed carbon steel (G450) specimens without and with zinc coating were conducted using the same test procedure and loading rate for specimens GF-R1, GF-R2, GF-R3, GF-R1-zinc, GF-R2-zinc and GF-R3-zinc. The thickness on each side of zinc coating was $0.05 \mathrm{~mm}$ for the coupon specimens in this study. The zinc coating is much softer than steel from a structural point of view, and so it is reasonable to assume the layer of zinc coating does not carry load, and the effective thickness of the steel is the base metal thickness (without the zinc coating) [20]. It is expected that the increased in cross-sectional area due to the zinc coating, and lead to a smaller values of initial Young's modulus $(E)$, static $0.2 \%$ proof stress $\left(\sigma_{0.2}\right)$ and static ultimate strength $\left(\sigma_{u}\right)$, as shown in Tables 11 . The initial Young's modulus, static $0.2 \%$ proof stress and static ultimate strength of series GF-R-zinc with zinc coating are $4.2 \%, 4.4 \%$ and $4.1 \%$ smaller than those of the companion series GF-R without zinc coating, respectively. This is mainly due to the larger cross-sectional area for coupon specimens with zinc coating in series GF-R-zinc. On average, the cross-sectional area of the coupon specimens with zinc coating is $4.2 \%$ larger than that without zinc coating (base metal). It is also stated in Clause X2.9 of the ASTM [9] that "heavy coatings should generally be removed from at least one grip end of flat specimens taken from coated products to permit accurate measurement of base metal thickness, assuming (a) the base metal properties are what are desired, (b) the coating does not contribute significantly to the strength of the product, and (c) coating removal can be easily accomplished. Otherwise, it may be advisable to leave the coating intact and determine the base metal thickness by an alternate method.” Therefore, it is recommended not to include the thickness of zinc coating in determining cross-sectional area for cold-formed steel.

Coupon specimens LF-R1, LF-R2, LF-R1-Instron and LF-R1-MTS250 were tested using MTS 50kN, Instron 4469 and MTS 250kN machines, respectively, with the same testing procedure and loading rate series $(\mathrm{R})$, as shown in Table 2 . The measured material properties and the stress-strain curves of the coupon specimens are shown in Table 11 and Fig. 7. It is shown that the test results obtained by static curves are generally similar to each other, 
despite the fact that using different testing machines. The initial Young's modulus ranged from 197.7 to $207.9 \mathrm{GPa}$; the $0.2 \%$ proof stress (yield strength) ranged from 593.7 to 639.2 $\mathrm{MPa}$, and the ultimate strength ranged from 720.9 to $732.7 \mathrm{MPa}$. These companion coupon specimens were extracted from the same batch of cold-formed lean duplex stainless steel material. Different material properties were found by using different testing machines. Compare with the material properties obtained by testing machine MTS 50kN, the material properties obtained by Instron 4469 and MTS $250 \mathrm{kN}$ machines are 1\% and 5.2\% different for Young's modulus, $7.7 \%$ and $5.5 \%$ different for $0.2 \%$ proof stress, and $1.4 \%$ and $0.3 \%$ different for ultimate strength, respectively.

\section{Proposed coupon test procedure}

\subsection{General}

In this study, a procedure to obtain the material properties of tensile coupon tests, including the preparation of test specimen, test setup, preloading, loading method and data analysis, is proposed. As mentioned earlier, initial curvature in the longitudinal direction of coupon specimen exists when the coupon extracted from cold-formed sections due to residual stresses. Therefore, it is imperative to obtain strains from both sides of the coupon specimens. It is also shown that the material properties obtained from coupon specimen, including the zinc coating in determining the cross-sectional area, are smaller than those obtained using cross-sectional area without considering zinc coating. Thus, it is important to remove the coating before measuring the cross-sectional area or subtract the thickness of coating in calculating the cross-sectional area. The loading rate specified in the AS [7], BSI [8] and ASTM [9] specifications, as shown in Table 2, is considered to be very fast from a research point of view and generally limited data were recorded. The fast loading rate applied on coupon specimen would lead to higher values of $0.2 \%$ proof stress and ultimate strength. Therefore, the loading rate should be carefully chosen, especially for the measurement of initial Young's modulus. The loading method for cold-formed steel, cold-formed stainless steel and aluminium alloy is shown in Table 17. During the coupon test, higher loading rate can be applied in the inelastic range of stress-strain curve, and an even higher loading rate can be applied at the post-ultimate stage. The detail procedure to obtain static material properties of 
flat and curved coupon specimens by tensile coupon tests are illustrated in the following two procedures. It should be noted that the loading rates recommended in Table 17 and the procedures are suitable for research purpose, with a total testing time of around 30 minutes. However, for the testing in the industry, which requires a much shorter testing time and allows slightly less accurate results, a higher loading rate series (e.g. $0.01 \mathrm{~min}^{-1}$ before yield strength and $0.5 \mathrm{~min}^{-1}$ after yield strength which is the lower-bound strain rate in the ASTM [9]) may also be used with static drop of not less than 60 seconds at yield and ultimate strengths. Such method substantially reduces the testing time to around 5 minutes, with less than $5 \%$ difference for the yield strength $\left(\sigma_{0.2}\right)$ and ultimate strength $\left(\sigma_{u}\right)$ obtained by the recommended method for research purpose.

\subsection{Procedure A: Static material properties of flat coupon specimens}

\section{Step A1 Preparation of test specimen}

A1-1 Extract a coupon specimen in the flat portion of section, and the dimension of the coupon should be prepared in accordance with the specifications (e.g. AS [7], BSI [8], ASTM [9] or any other international specifications).

A1-2 Remove surface coating of the coupon specimen by acid-etching (for specimens with coating).

A1-3 Measure the cross-sectional area on the base metal or subtract the thickness of coating.

A1-4 Clean the surface of the specimen in the middle of the gauge length. Mark the gauge length.

A1-5 Attach strain gauges on both sides of the coupon in the longitudinal direction at midlength.

\section{Step A2 Set-up}

A2-1 Clamp the upper part of the coupon specimen. Ensure the coupon specimen is in line with the direction of the applied load (e.g. using laser measurement device or leveling instrument).

A2-2 Set the loading to zero, then clamp the lower part of the coupon specimen.

A2-3 Mount the extensometer onto the specimen at the marked lines of gauge length.

\section{Step A3 Preload}

A3-1 Apply tensile load to the specimen, which is smaller than the proportional limit. In this study, the proportional limit was $75.7 \%, 59.8 \%, 65.2$ and $47.8 \%$ of the nominal $0.2 \%$ proof stresses $\left(\sigma_{0.2}\right)$ for cold-formed carbon steel (G450), cold-formed lean 
duplex and ferritic stainless steel, and aluminium T6 alloy flat coupons, respectively, as shown in Tables $7-10$. Therefore, it is suggested that an upper limit of approximately $50 \%, 40 \%, 45 \%$ and $30 \%$ of the nominal $\sigma_{0.2}$ in preloading flat coupons can be applied for cold-formed carbon steel (G450), cold-formed lean duplex and ferritic stainless steel and aluminium T6 alloy, respectively.

A3-2 Observe the stress-strain relationship during preloading. Ensure the strain gauges and extensometer are working properly.

A3-3 Unload the coupon specimen to zero load, and reset the extensometer and strain gauges to zero reading.

\section{Step A4 Loading method}

A4-1 Table 17 shows the proposed loading procedure and loading rate at different strains for cold-formed steel, cold-formed stainless steel and aluminium alloy coupon tests.

A4-2 Adopt a low strain rate at the beginning of the test from zero to proportional limit, so that sufficient data can be obtained to determine the Young's modulus. It is suggested that $0.05 \mathrm{~mm} / \mathrm{min}$ under stroke control be adopted in the elastic range of the stressstrain curve.

A4-3 Higher strain rate should be adopted from proportional limit to the ultimate strength. It is suggested that $0.4 \mathrm{~mm} / \mathrm{min}$ under stroke control be adopted for cold-formed carbon steel and aluminium alloy, while $0.8 \mathrm{~mm} / \mathrm{min}$ is used for cold-formed stainless steel.

A4-4 During the loading process, straining is paused near the $0.2 \%$ proof stress and ultimate strength for 100 seconds, as shown in Table 17. Such procedure allows the stress relaxation to take place, and thus the static material properties can be obtained.

A4-5 After the stress relaxation at ultimate strength, an even higher loading rate is applied in the post-ultimate range of the stress-strain curve until the coupon specimen fracture. It is suggested that $0.8 \mathrm{~mm} / \mathrm{min}$ under stroke control be adopted for cold-formed carbon steel and aluminium alloy, while $2.0 \mathrm{~mm} / \mathrm{min}$ is used for cold-formed stainless steel.

A4-6 Stop the loading machine and remove the failed coupon specimen. Extract the following test data: (i) applied load; (ii) strains measured from the two strain gauges; (iii) strains measured from the extensometer.

\section{Step A5 Data analysis}

A5-1 Obtain stresses by dividing the applied tensile load with the measured cross-sectional 
area. Plot a stress-strain curve using the average strain measured by the two strain gauges in the initial part of the stress-strain curve, and extensometer readings were used for the rest of the curve.

A5-2 Initial Young's modulus $(E)$ is determined from the slope of the initial linear portion obtained from the strain gauge readings, as shown in Fig. 21. It is suggested that the stress intervals for the determination of initial Young's modulus in the slope of the initial linear portion are $20-45 \%$ of the nominal $\sigma_{0.2}$ for cold-formed carbon steel and stainless steel flat coupons, $25-35 \%$ of the nominal $\sigma_{0.2}$ for aluminium alloy.

A5-3 Draw a straight line from origin with the slope equal to the initial Young's modulus. Shift the stress-strain curve, so that the elastic range of the curve overlaps with the straight line. The shift of the stress-strain curve is to correct the influence of the possible initial curvature in the coupon specimens at the beginning of the tests.

A5-4 The proportional limit $\left(\sigma_{p}\right)$ is determined at the point of separation between the straight line and the stress-strain curve, as shown in Fig. 21 and 22.

A5-5 Now, the strains obtained from extensometer are used. The stress-strain curve plotted using the extensometer readings was shifted horizontally to meet the proportional limit. The combined stress-strain curve consists of two parts. The initial part of the curve was plotted using strain gauge readings until the proportional limit, and the rest of the curve was plotted using extensometer readings until fracture, as shown in Fig. 22.

A5-6 The static stress-strain curve is obtained by considering the two static drops for stress relaxation near the $0.2 \%$ proof stress $\left(\sigma_{0.2}\right)$ and ultimate strength $\left(\sigma_{u}\right)$. For those stressstrain curves with rounded shape (e.g. stainless steel, alumimium alloy and high strength steel), the first part of the stress-strain curve is obtained from origin to proportional limit $\left(\sigma_{p}\right)$. The second part of the curve is obtained from $\sigma_{p}$ to the first static drop near the $\sigma_{0.2}$, where the stress reduced in proportion with strain between the $\sigma_{p}$ and $\sigma_{0.2}$. The third part of the curve is obtained from $\sigma_{0.2}$ to $\sigma_{u}$, and the stress reduced in proportion with strain between these two points, as shown in Fig. 23(a). The last part of the stress-strain curve from $\sigma_{u}$ until fracture is plotted using the static drop at $\sigma_{u}$. For those stress-strain curves with yield plateau (e.g. carbon steel), the stress in the plateau reduced by the same amount of static drop at the yield strength, as shown in Fig. 23(b).

A5-7 The static $0.2 \%$ proof stress (yield strength) is determined by the intersect point of the 
static stress-strain curve and the shifted straight line from the origin to $0.2 \%$ strain, as shown in Fig. 24.

A5-8 The static ultimate strength is determined from the maximum stress of the static stress-strain curve, and the strain at fracture is obtained from the strain prior to considerably reduction of tensile force due to fracture of specimen, as shown in Fig. 25.

\subsection{Procedure B: Static material properties of curved coupon specimens}

\section{Step B1 Preparation of test specimen}

Identical to procedure A.

\section{Step B2 Set-up}

B2-1 Clamp the two special heads in the testing machine, and install the upper part of the curved coupon into the upper special head using a pin, as shown in Fig. 3(b). Ensure the coupon specimen is in line with the direction of the applied load (e.g. using laser measurement device or leveling instrument).

B2-2 Set the loading to zero, and put the other pin through the lower special head and the lower part of the curved coupon specimen, as shown in Fig. 3(b).

B2-3 Mount the extensometer onto the specimen at the marked lines of gauge length.

\section{Step B3 - Preload}

B3-1 The extensometer and strain gauges are set to zero reading. Apply tensile load to the specimen, which is smaller than the proportional limit. In this study, the proportional limit was $44 \%$ and $75 \%$ of the nominal $0.2 \%$ proof stresses $\left(\sigma_{0.2}\right)$ for cold-formed carbon steel (G450) and cold-formed lean duplex stainless steel curved coupons, as shown in Table 11. Therefore, it is suggested that an upper limit of approximately $30 \%$ and $50 \%$ of the nominal $\sigma_{0.2}$ in preloading curved coupons can be applied for coldformed carbon steel (G450) and cold-formed lean duplex stainless steel, respectively.

B3-2 Observe the stress-strain relationship during preloading. Ensure the strain gauges and extensometer are working well.

B3-3 Unload the curved coupon specimen to a small stress, say approximately $5 \mathrm{MPa}$, in order to eliminate any gap between the pins and the curved coupon specimen.

\section{Step B4 Loading method}

Identical to the procedure A, except that the loading rate from proportional limit to fracture are suggested to be 0.4 and $0.8 \mathrm{~mm} / \mathrm{min}$ under stroke control for cold-formed carbon steel 
(G450) and cold-formed lean duplex stainless steel, respectively, as shown in Table 17.

\section{Step B5 - Data analysis}

Identical to the procedure A, except that the stress interval of $45-65 \%$ of the nominal $\sigma_{0.2}$ for cold-formed carbon steel and stainless steel curved coupons is suggested to determine the initial Young's modulus.

\section{Conclusions}

Tensile coupon test is commonly used to obtain the material properties of metallic materials. However, inconsistent coupon test procedure and data analysis leads to inaccurate results. Conducting an accurate coupon test for metallic material requires deliberate and careful thoughts in every procedure. In this study, the existing specifications and literature on tensile coupon tests have been reviewed. Various test and data analysis procedures to obtain the material properties are discussed. The coupon tests were conducted on cold-formed carbon steel, cold-formed stainless steel and aluminium alloy using different methods and procedures. It is shown that the strain rate affects the dynamic stress-strain curve, and it is recommended that the static stress-strain curve should be used to determine the material properties. Three different methods to determine the initial Young's modulus are used, and the corresponding test results are compared. The slope of linear potion method together with the suggested stress intervals for different metallic materials is recommended for the determination of initial Young's modulus. Furthermore, three different methods for the determination of crosssectional area of curved coupon specimens were examined. The AutoCAD method and geometrical equations method are recommended to measure the cross-sectional area of curved coupons. For the coupon specimens with coating, it is recommended not to include the thickness of the coating in determining the cross-sectional area of cold-formed steel. The loading rates to be used during coupon tests are also suggested in this study. Detail procedures to obtain static material properties of tensile coupon tests including the preparation of test specimen, test setup, preloading, loading method and data analysis, are proposed. 


\section{Acknowledgements}

The authors are grateful to STALA Tube Finland for supplying the stainless steel test specimens. The research work described in this paper was supported by a grant from The University of Hong Kong under the seed funding program for basic research.

\section{Notations}

A cross-sectional area of flat coupon

$A_{c} \quad$ cross-sectional area of curved coupon that determined using the AutoCAD method

$A_{g} \quad$ cross-sectional area of curved coupon that determined using the geometrical equations

$A_{w} \quad$ cross-sectional area of curved coupon that determined using the weight and density method

$A_{1} \quad$ part of the cross-sectional area of curved coupon

$A_{2} \quad$ part of the cross-sectional area of curved coupon

$A_{3} \quad$ part of the cross-sectional area of curved coupon

$A_{4} \quad$ part of the cross-sectional area of curved coupon

a parameter in the equation to calculate the cross-sectional area of curved coupons

B overall width of cross-section of specimen; width of steel sheet; width of crosssection of coupon specimen

COV coefficient of variation

D overall depth of cross-section of specimen; depth of steel sheet

E initial Young's modulus

$H \quad$ overall height of the cross-section of curved coupon specimen

$n \quad$ Ramberg-Osgood parameter

$r_{i} \quad$ inner radius of cross-section of curved coupon specimen

$r_{o} \quad$ outer radius of cross-section of curved coupon specimen

$x \quad$ parameter in the equation to calculate the cross-sectional area of curved coupons 
thickness of cross-section of specimen

$t_{o} \quad$ thickness between mid-points of outer and inner curved surfaces

$t_{1} \quad$ heights at the edge of the cross-section of curved coupon specimen

$t_{2}$ heights at the edge of the cross-section of curved coupon specimen

$\Delta_{a} \quad$ different amount of drops of stress after static drops

$\Delta_{b} \quad$ different amount of drops of stress before static drops

$\Delta_{s, t} \quad$ stress reduced for a specified period of time during stress relaxation

$\Delta_{X} \quad$ reduced amount of stress at static drop corresponding to $\varepsilon_{X}$

$\Delta_{0} \quad$ reduced amount of stress at the static drop corresponding to $\varepsilon_{0}$

$\Delta_{1} \quad$ reduced amount of stress at the static drop corresponding to $\varepsilon_{u}$

$\Delta_{2} \quad$ reduced amount of stress after the static drop corresponding to $\varepsilon_{u}$

$\varepsilon_{f} \quad$ tensile strain at fracture

$\varepsilon_{p} \quad$ tensile strain at elastic limit

$\varepsilon_{u} \quad$ tensile strain at ultimate strength

$\varepsilon_{x} \quad$ tensile strain at any location between $\varepsilon_{0}$ and $\varepsilon_{u}$

$\varepsilon_{0} \quad$ tensile strain at the static drop

$\varepsilon_{0.2} \quad$ tensile strain at $0.2 \%$ proof stress

$\varepsilon_{1} \quad$ strain value of 0.0005

$\varepsilon_{2} \quad$ strain value of 0.0025

$\sigma_{o} \quad$ stress prior to static drop

$\sigma_{p} \quad$ stress at proportional limit

$\sigma_{u} \quad$ ultimate strength

$\sigma_{y} \quad$ yield strength

$\sigma_{0.2} \quad 0.2 \%$ proof stress (yield strength)

$\sigma_{1} \quad$ stress measured at the strain value $\varepsilon_{1}=0.0005$

$\sigma_{2} \quad$ stress measured at the strain value $\varepsilon_{2}=0.0025$ 


\section{References}

[1] Hoge KG, Mukherjee AK. The temperature and strain rate dependence of the flow stress of tantalum. Journal of Materials Science 1977; 12(8): 1666 - 72.

[2] Krempl E. An experimental study of room-temperature rate sensitivity, creep and relaxation of AISI Type 304 Stainless Steel. Journal of Mechanics and Physics of Solids 1979; 27(5-6): $363-75$.

[3] Khan AS, Liang R. Behaviors of three BCC metal over a wide range of strain rates and temperatures: Experiments and modeling. International Journal of Plasticity 1999; 15(10): 1089 - 1109.

[4] Krempl E. Relaxation behavior and modeling. International Journal of Plasticity 2001; 17(10): $1419-36$.

[5] Krempl E, Khan F. Rate (time)-dependent deformation behavior: an overview of some properties of metals and solid polymers. International Journal of Plasticity 2003; 19(7): 1069 $-95$.

[6] Pan CL, Wu S, Yu WW. Strain rate and aging effect on the mechanical properties of sheet steels. Thin-walled Structures 2001; 39: 429 - 44.

[7] AS. Metallic materials - tensile testing at ambient temperature. Australian Standard, AS 1391-2007. Sydney (Australia).Standards Association of Australia; 2007.

[8] BSI. Metallic materials - Tensile testing - Part 1: Method of test at ambient temperature. British Standards, BS EN ISO 6892-1, CEN, Brussels; 2009.

[9] ASTM. Standard test methods for tension testing of metallic materials. E8/E8M-13a. West Conshohocken, USA: American Society for Testing and Materials; 2013.

[10] Huang Y, Young B. Material properties of cold-formed lean duplex stainless steel sections. Journal of Thin-walled Structures 2012; 54: 72 - 81.

[11] Zhu JH, Young B. Design of Aluminum Alloy Flexural Members Using Direct Strength Method. Journal of Structural Engineering 2009; 135(5): 558 - 566.

[12] Saliba N, Gardner L. Cross-section stability of lean duplex stainless steel welded Isections. Journal of Constructional Steel Research 2013; 80: 1 - 14.

[13] Guide to Stability Design Criteria for Metal Structures, Edited by Ziemian RD. 6th Edition. John Wiley \& Sons, Inc., Hoboken, New Jersey; 2010.

[14] Theofanous M, Gardner L. Testing and numerical modelling of lean duplex stainless steel hollow section columns. Eng Struct 2009; 31(12): 3047 - 3058. 
[15] Chen J, Young B. Corner properties of cold-formed steel sections at elevated temperatures. Thin-Walled Structures 2006; 44: 216 - 223

[16] Afshan S, Rossi B, Gardner L. Strength enhancements in cold-formed structural sections - Part I: Material testing. Journal of Constructional Steel Research 2013; 83: 177 - 188.

[17] EN ISO. Plastics - Determination of tensile properties - Part 1: General principles. EN ISO 527-1, CEN, Brussels; 1996.

[18] Young B. Tests and design of fixed-ended cold-formed steel plain angle columns. Journal of structural engineering 2004; 130(12): 1931 - 1940.

[19] AutoCAD 2010 User’s Guide. Autodesk Inc., AutoCAD 2010, USA; 2010.

[20] Young B, Rasmussen KJR. Design of lipped channel columns. Journal of Structural Engineering 1998; 124(2): 140 - 148. 


\begin{tabular}{c|ccccccc|ccc}
\hline $\begin{array}{c}\text { Curved } \\
\text { specimen }\end{array}$ & $\begin{array}{c}t_{o} \\
(\mathrm{~mm})\end{array}$ & $\begin{array}{c}t_{1} \\
(\mathrm{~mm})\end{array}$ & $\begin{array}{c}t_{2} \\
(\mathrm{~mm})\end{array}$ & $\begin{array}{c}B \\
(\mathrm{~mm})\end{array}$ & $\begin{array}{c}H \\
(\mathrm{~mm})\end{array}$ & $\begin{array}{c}r_{i} \\
(\mathrm{~mm})\end{array}$ & $\begin{array}{c}r_{o} \\
(\mathrm{~mm})\end{array}$ & $\begin{array}{c}A_{w} \\
\left(\mathrm{~mm}^{2}\right)\end{array}$ & $\begin{array}{c}A_{c} \\
\left(\mathrm{~mm}^{2}\right)\end{array}$ & $\begin{array}{c}A_{g} \\
\left(\mathrm{~mm}^{2}\right)\end{array}$ \\
\hline GC-R1 & 1.78 & 2.50 & 2.64 & 3.89 & 3.04 & 1.00 & 3.25 & 8.50 & 8.35 & 8.37 \\
GC-R2 & 1.67 & 2.49 & 2.49 & 3.94 & 2.92 & 1.00 & 3.75 & 8.05 & 8.02 & 8.10 \\
\hline LC-R1 & 2.93 & 3.38 & 3.51 & 3.80 & 4.07 & 1.25 & 3.60 & 13.67 & 12.06 & 12.08 \\
LC-R2 & 2.93 & 3.65 & 3.90 & 3.96 & 4.13 & 0.50 & 3.25 & 12.69 & 13.22 & 13.47 \\
\hline
\end{tabular}

Table 1: Dimension of curved coupon specimens

\begin{tabular}{c|cccc}
\hline \multirow{2}{*}{ Series } & \multicolumn{4}{|c}{ Strain rate $\times 10^{-3}\left(\mathrm{~min}^{-1}\right)$} \\
\cline { 2 - 5 } & before $\sigma_{p}$ & $\sigma_{p}$ to $\sigma_{y}$ & $\sigma_{y}$ to $\sigma_{u}$ & $\sigma_{u}$ to fracture \\
\hline GF-S & 0.3 & 0.3 & 0.3 & 3.8 \\
GF-R & 0.3 & 3.8 & 3.8 & 12 \\
GF-L & 5 & 5 & 45 & 45 \\
GF-U & 30 & 30 & 460 & 460 \\
GC-R & 0.2 & 2.5 & 2.5 & 12 \\
\hline LF-R & 0.3 & 13 & 13 & 35 \\
LF-L & 6 & 6 & 44 & 44 \\
LF-U & 20 & 20 & 440 & 440 \\
LC-R & 0.2 & 28 & 28 & 37 \\
\hline FF-S & 0.3 & 0.3 & 7 & 18 \\
FF-R & 0.3 & 13 & 13 & 36 \\
FF-L & 8 & 8 & 50 & 50 \\
FF-U & 25 & 25 & 490 & 490 \\
\hline AF-R & 0.4 & 7 & 7 & 14 \\
AF-L & 12 & 12 & 50 & 50 \\
AF-U & 25 & 25 & 400 & 400 \\
\hline AS [7] & --- & $15-150$ & $<480$ & --- \\
BSI [8] & --- & $<15$ & $<402$ & --- \\
ASTM [9] & --- & $9-21$ & $50-500$ & --- \\
\hline
\end{tabular}

Table 2: Strain rates for coupon tests 


\begin{tabular}{|c|c|c|c|c|c|c|c|c|c|c|c|c|c|c|c|c|}
\hline \multirow{2}{*}{$\begin{array}{c}\text { Material } \\
\text { properties }\end{array}$} & \multicolumn{16}{|c|}{ Dynamic curves } \\
\hline & GF-S1 & GF-S2 & GF-S3 & Mean & GF-R1 & GF-R2 & GF-R3 & Mean & GF-L1 & GF-L2 & GF-L3 & Mean & GF-U1 & GF-U2 & GF-U3 & Mean \\
\hline$E(\mathrm{GPa})$ & 217.9 & 214.5 & 216.7 & 216.4 & 213.9 & 219.0 & 218.6 & 217.2 & 227.0 & 218.7 & 220.6 & 222.1 & 221.5 & 221.0 & 218.5 & 220.3 \\
\hline$\sigma_{0.2}(\mathrm{MPa})$ & 511.6 & 516.6 & 524.2 & 517.5 & 512.9 & 526.5 & 527.7 & 522.4 & 535.8 & 534.0 & 537.2 & 535.7 & 532.1 & 533.7 & 532.1 & 532.6 \\
\hline$\sigma_{u}(\mathrm{MPa})$ & 540.3 & 544.2 & 552.7 & 545.7 & 543.2 & 556.4 & 556.6 & 552.1 & 566.7 & 562.8 & 566.8 & 565.4 & 565.2 & 570.5 & 565.2 & 567.0 \\
\hline$n$ & 17.5 & 23.6 & 30.6 & 23.9 & 23.5 & 24.3 & 28.2 & 25.3 & 19.6 & 22.2 & 22.4 & 21.4 & 25.0 & 28.8 & 23.7 & 25.8 \\
\hline$\sigma_{u} / \sigma_{0.2}$ & 1.06 & 1.05 & 1.05 & 1.05 & 1.06 & 1.06 & 1.05 & 1.06 & 1.06 & 1.05 & 1.06 & 1.06 & 1.06 & 1.07 & 1.06 & 1.06 \\
\hline
\end{tabular}

Table 3: Material properties of carbon steel G450 coupon specimens

\begin{tabular}{c|ccc|ccc|ccc}
\hline Material & \multicolumn{8}{|c}{ Dynamic curves } \\
\cline { 2 - 10 } properties & LF-R1 & LF-R2 & Mean & LF-L1 & LF-L2 & Mean & LF-U1 & LF-U2 & Mean \\
\hline$E(\mathrm{GPa})$ & 197.7 & 197.8 & 197.8 & 202.6 & 200.7 & 201.7 & 198.5 & 205.4 & 202.0 \\
$\sigma_{0.2}(\mathrm{MPa})$ & 654.1 & 647.7 & 650.9 & 668.5 & 654.1 & 661.3 & 672.8 & 662.3 & 667.6 \\
$\sigma_{u}(\mathrm{MPa})$ & 786.5 & 788.8 & 787.7 & 797.6 & 798.7 & 798.2 & 811.6 & 809.1 & 810.4 \\
$n$ & 8.5 & 7.8 & 8.2 & 5.8 & 8.4 & 7.1 & 8.3 & 6.7 & 7.5 \\
$\sigma_{u} / \sigma_{0.2}$ & 1.20 & 1.22 & 1.21 & 1.19 & 1.22 & 1.21 & 1.21 & 1.22 & 1.22 \\
\hline
\end{tabular}

Table 4: Material properties of lean duplex stainless steel coupon specimens

\begin{tabular}{|c|c|c|c|c|c|c|c|c|c|c|c|c|c|c|c|c|}
\hline \multirow{2}{*}{$\begin{array}{c}\text { Material } \\
\text { properties }\end{array}$} & \multicolumn{16}{|c|}{ Dynamic curves } \\
\hline & FF-S1 & FF-S2 & FF-S3 & Mean & FF-R1 & FF-R2 & FF-R3 & Mean & FF-L1 & FF-L2 & FF-L3 & Mean & FF-U1 & FF-U2 & FF-U3 & Mean \\
\hline$E(\mathrm{GPa})$ & 204.8 & 203.6 & 202.2 & 203.5 & 211.4 & 204.6 & 202.1 & 206.0 & 211.6 & 211.2 & 206.5 & 209.8 & 212.4 & 206.9 & 205.5 & 208.3 \\
\hline$\sigma_{0.2}(\mathrm{MPa})$ & 473.3 & 483.2 & 459.4 & 472.0 & 484.9 & 481.6 & 478.1 & 481.5 & 478.5 & 482.1 & 492.6 & 484.4 & 488.0 & 490.0 & 480.7 & 486.2 \\
\hline$\sigma_{u}(\mathrm{MPa})$ & 496.0 & 498.9 & 489.3 & 494.7 & 503.6 & 501.3 & 495.1 & 500.0 & 507.2 & 510.1 & 511.4 & 509.6 & 516.4 & 522.5 & 518.2 & 519.0 \\
\hline$n$ & 6.8 & 7.5 & 6.6 & 7.0 & 7.8 & 7.2 & 7.6 & 7.5 & 6.2 & 6.4 & 7.7 & 6.8 & 7.4 & 6.8 & 6.9 & 7.0 \\
\hline$\sigma_{u} / \sigma_{0.2}$ & 1.05 & 1.03 & 1.07 & 1.05 & 1.04 & 1.04 & 1.04 & 1.04 & 1.06 & 1.06 & 1.04 & 1.05 & 1.06 & 1.07 & 1.08 & 1.07 \\
\hline
\end{tabular}

Table 5: Material properties of ferritic stainless steel coupon specimens 


\begin{tabular}{c|cccc|ccccc|cccc}
\hline Material & \multicolumn{10}{c}{ Dynamic curves } \\
\cline { 2 - 13 } properties & AF-R1 & AF-R2 & AF-R3 & Mean & AF-L1 & AF-L2 & AF-L3 & Mean & AF-U1 & AF-U2 & AF-U3 & Mean \\
\hline$E(\mathrm{GPa})$ & 67.3 & 66.4 & 67.0 & 66.9 & 66.7 & 71.0 & 66.3 & 68.0 & 66.4 & 66.7 & 66.0 & 66.4 \\
$\sigma_{0.2}(\mathrm{MPa})$ & 250.1 & 249.0 & 248.0 & 249.0 & 250.8 & 247.6 & 259.7 & 252.7 & 251.8 & 260.0 & 267.3 & 259.7 \\
$\sigma_{u}(\mathrm{MPa})$ & 272.4 & 270.9 & 271.4 & 271.6 & 274.0 & 273.6 & 282.2 & 276.6 & 276.0 & 283.3 & 289.5 & 282.9 \\
$n$ & 7.4 & 8.9 & 7.0 & 7.8 & 8.7 & 9.5 & 7.7 & 8.6 & 8.9 & 8.6 & 9.6 & 9.0 \\
$\sigma_{u} / \sigma_{0.2}$ & 1.09 & 1.09 & 1.09 & 1.09 & 1.09 & 1.10 & 1.09 & 1.09 & 1.10 & 1.09 & 1.08 & 1.09 \\
\hline
\end{tabular}

Table 6: Material properties of aluminium coupon specimens

\begin{tabular}{c|ccc|ccc|cccc|cccc}
\hline \multirow{2}{*}{$\begin{array}{c}\text { Material } \\
\text { properties }\end{array}$} & \multicolumn{10}{|c}{ Static curves } \\
\cline { 2 - 14 } & GF-S1 & GF-S2 & GF-S3 & GF-R1 & GF-R2 & GF-R3 & GF-L1 & GF-L2 & GF-L3 & GF-U1 & GF-U2 & GF-U3 & Mean & COV \\
\hline$E(\mathrm{GPa})$ & 217.9 & 214.5 & 216.7 & 213.9 & 219.0 & 218.6 & 227.0 & 218.7 & 220.6 & 221.5 & 221.0 & 218.5 & 219.0 & 0.016 \\
$\sigma_{p}(\mathrm{MPa})$ & 334.1 & 322.3 & 329.3 & 319.0 & 369.5 & 303.4 & 307.1 & 393.5 & 354.1 & 329.2 & 368.0 & 360.2 & 340.8 & 0.082 \\
$\varepsilon_{p}(\%)$ & 0.15 & 0.15 & 0.15 & 0.15 & 0.17 & 0.14 & 0.14 & 0.18 & 0.16 & 0.15 & 0.17 & 0.17 & 0.16 & 0.083 \\
$\sigma_{0.2}(\mathrm{MPa})$ & 489.0 & 492.6 & 496.8 & 495.3 & 498.4 & 497.7 & 503.5 & 502.2 & 496.1 & 490.2 & 486.1 & 494.2 & 495.2 & 0.010 \\
$\varepsilon_{0.2}(\%)$ & 0.43 & 0.43 & 0.43 & 0.44 & 0.42 & 0.43 & 0.42 & 0.43 & 0.43 & 0.42 & 0.43 & 0.43 & 0.43 & 0.013 \\
$\sigma_{u}(\mathrm{MPa})$ & 512.4 & 519.3 & 525.3 & 512.6 & 526.8 & 526.8 & 531.0 & 525.7 & 527.1 & 515.9 & 516.8 & 515.4 & 521.3 & 0.012 \\
$\varepsilon_{u}(\%)$ & 6.6 & 6.5 & 6.7 & 7.4 & 7.0 & 7.0 & 7.4 & 6.9 & 7.0 & 7.1 & 7.1 & 6.6 & 6.9 & 0.043 \\
$\varepsilon_{f}(\%)$ & 12.0 & 12.5 & 11.5 & 13.3 & 12.1 & 11.7 & 13.3 & 13.5 & 12.9 & 12.9 & 12.8 & 12.9 & 12.6 & 0.052 \\
$n$ & 17.6 & 21.7 & 21.7 & 23.5 & 25.4 & 18.6 & 16.5 & 27.4 & 22.8 & 18.3 & 38.9 & 28.0 & 23.4 & 0.264 \\
$\sigma_{u} / \sigma_{0.2}$ & 1.04 & 1.05 & 1.05 & 1.04 & 1.06 & 1.06 & 1.05 & 1.05 & 1.06 & 1.05 & 1.06 & 1.04 & 1.05 & 0.008 \\
\hline
\end{tabular}

Table 7: Summary of tensile coupon test results for G450 obtained from static curves 


\begin{tabular}{c|cc|cc|cc|cc}
\hline Material & \multicolumn{8}{|c}{ Static curves } \\
\cline { 2 - 9 } properties & LF-R1 & LF-R2 & LF-L1 & LF-L2 & LF-U1 & LF-U2 & Mean & COV \\
\hline$E(\mathrm{GPa})$ & 197.7 & 197.8 & 202.6 & 200.7 & 198.5 & 205.4 & 200.5 & 0.015 \\
$\sigma_{p}(\mathrm{MPa})$ & 255.1 & 269.2 & 270.9 & 242.3 & 360.0 & 217.4 & 269.2 & 0.181 \\
$\varepsilon_{p}(\%)$ & 0.13 & 0.14 & 0.13 & 0.12 & 0.18 & 0.11 & 0.14 & 0.180 \\
$\sigma_{0.2}(\mathrm{MPa})$ & 593.7 & 599.3 & 626.2 & 603.2 & 638.0 & 612.4 & 612.1 & 0.028 \\
$\varepsilon_{0.2}(\%)$ & 0.52 & 0.51 & 0.52 & 0.50 & 0.52 & 0.50 & 0.51 & 0.019 \\
$\sigma_{u}(\mathrm{MPa})$ & 722.6 & 720.9 & 726.1 & 720.06 & 703.0 & 705.6 & 716.4 & 0.013 \\
$\varepsilon_{u}(\%)$ & 22.3 & 24.0 & 21.5 & 23.9 & 17.4 & 19.9 & 21.5 & 0.118 \\
$\varepsilon_{f}(\%)$ & 37.6 & 36.0 & 37.8 & 32.0 & 34.8 & 30.0 & 34.7 & 0.090 \\
$n$ & 8.9 & 7.4 & 5.7 & 7.5 & 8.3 & 5.4 & 7.2 & 0.194 \\
$\sigma_{u} / \sigma_{0.2}$ & 1.22 & 1.20 & 1.16 & 1.19 & 1.10 & 1.15 & 1.17 & 0.037 \\
\hline
\end{tabular}

Table 8: Summary of tensile coupon test results for lean duplex stainless steel obtained from static curves

\begin{tabular}{|c|c|c|c|c|c|c|c|c|c|c|c|c|c|c|}
\hline \multirow{2}{*}{$\begin{array}{c}\text { Material } \\
\text { properties }\end{array}$} & \multicolumn{14}{|c|}{ Static curves } \\
\hline & FF-S1 & FF-S2 & FF-S3 & FF-R1 & FF-R2 & FF-R3 & FF-L1 & FF-L2 & FF-L3 & FF-U1 & FF-U2 & FF-U3 & Mean & COV \\
\hline$E(\mathrm{GPa})$ & 204.8 & 203.6 & 202.2 & 211.4 & 204.6 & 202.1 & 211.6 & 211.2 & 206.5 & 212.4 & 206.9 & 205.5 & 206.9 & 0.018 \\
\hline$\sigma_{p}(\mathrm{MPa})$ & 181.4 & 210.5 & 160.1 & 202.2 & 178.5 & 198.9 & 161.7 & 138.7 & 186.6 & 156.5 & 210.0 & 204.5 & 182.5 & 0.131 \\
\hline$\varepsilon_{p}(\%)$ & 0.09 & 0.10 & 0.08 & 0.10 & 0.09 & 0.10 & 0.08 & 0.07 & 0.09 & 0.07 & 0.10 & 0.10 & 0.09 & 0.131 \\
\hline$\sigma_{0.2}(\mathrm{MPa})$ & 454.1 & 462.2 & 440.4 & 464.9 & 458.9 & 457.8 & 458.1 & 461.9 & 472.3 & 465.8 & 461.1 & 451.2 & 459.1 & 0.018 \\
\hline$\varepsilon_{0.2}(\%)$ & 0.42 & 0.43 & 0.42 & 0.42 & 0.43 & 0.43 & 0.42 & 0.43 & 0.43 & 0.43 & 0.41 & 0.42 & 0.42 & 0.016 \\
\hline$\sigma_{u}(\mathrm{MPa})$ & 465.5 & 467.1 & 455.7 & 467.2 & 464.3 & 461.5 & 470.7 & 472.2 & 474.8 & 469.9 & 473.2 & 466.1 & 467.4 & 0.011 \\
\hline$\varepsilon_{u}(\%)$ & 12.6 & 14.3 & 14.4 & 13.9 & 12.5 & 14.6 & 12.9 & 10.9 & 9.0 & 8.5 & 7.7 & 9.5 & 11.7 & 0.214 \\
\hline$\varepsilon_{f}(\%)$ & 24.4 & 21.9 & 23.5 & 23.0 & 23.6 & 23.6 & 22.6 & 20.0 & 19.0 & 20.0 & 18.4 & 21.8 & 21.8 & 0.092 \\
\hline$n$ & 6.7 & 7.5 & 6.4 & 7.8 & 6.9 & 8.1 & 6.3 & 6.2 & 7.7 & 6.7 & 7.1 & 7.3 & 7.1 & 0.089 \\
\hline$\sigma_{u} / \sigma_{0.2}$ & 1.03 & 1.01 & 1.03 & 1.00 & 1.01 & 1.01 & 1.03 & 1.02 & 1.01 & 1.01 & 1.03 & 1.03 & 1.02 & 0.011 \\
\hline
\end{tabular}

Table 9: Summary of tensile coupon test results for ferritic stainless steel obtained from static curves 


\begin{tabular}{c|ccc|ccc|ccc|cc}
\hline \multirow{2}{*}{$\begin{array}{c}\text { Material } \\
\text { properties }\end{array}$} & \multicolumn{10}{c}{ Static curves } \\
\cline { 2 - 12 } & AF-R1 & AF-R2 & AF-R3 & AF-L1 & AF-L2 & AF-L3 & AF-U1 & AF-U2 & AF-U3 & Mean & COV \\
\hline$E(\mathrm{GPa})$ & 67.3 & 66.4 & 67.0 & 66.7 & 71.0 & 66.3 & 66.4 & 66.7 & 66.0 & 67.1 & 0.023 \\
$\sigma_{p}(\mathrm{MPa})$ & 122.8 & 111.3 & 132.1 & 110.4 & 132.1 & 111.5 & 115.0 & 102.8 & 138.0 & 119.6 & 0.102 \\
$\varepsilon_{p}(\%)$ & 0.18 & 0.17 & 0.20 & 0.17 & 0.20 & 0.17 & 0.17 & 0.16 & 0.21 & 0.18 & 0.097 \\
$\sigma_{0.2}(\mathrm{MPa})$ & 245.3 & 243.1 & 239.4 & 244.4 & 240.5 & 251.1 & 247.6 & 251.6 & 259.4 & 246.9 & 0.025 \\
$\varepsilon_{0.2}(\%)$ & 0.57 & 0.57 & 0.56 & 0.57 & 0.55 & 0.58 & 0.57 & 0.58 & 0.58 & 0.57 & 0.018 \\
$\sigma_{u}(\mathrm{MPa})$ & 254.8 & 254.9 & 252.9 & 254.6 & 250.6 & 260.5 & 253.8 & 259.4 & 263.1 & 256.1 & 0.016 \\
$\varepsilon_{u}(\%)$ & 5.8 & 5.8 & 5.2 & 6.3 & 5.2 & 5.5 & 6.3 & 6.0 & 6.7 & 5.9 & 0.088 \\
$\varepsilon_{f}(\%)$ & 7.6 & 7.5 & 7.2 & 7.7 & 6.8 & 7.7 & 8.0 & 8.6 & 8.2 & 7.7 & 0.069 \\
$n$ & 7.2 & 7.9 & 8.6 & 8.6 & 8.9 & 8.9 & 9.0 & 7.1 & 8.2 & 8.3 & 0.088 \\
$\sigma_{u} / \sigma_{0.2}$ & 1.05 & 1.05 & 1.06 & 1.04 & 1.04 & 1.04 & 1.03 & 1.03 & 1.01 & 1.04 & 0.014 \\
\hline
\end{tabular}

Table 10: Summary of tensile coupon test results for aluminium alloy obtained from static curves

\begin{tabular}{c|ccc|cc|cc|cc}
\hline \multirow{2}{*}{$\begin{array}{c}\text { Material } \\
\text { properties }\end{array}$} & \multicolumn{10}{|c}{ Static curves } \\
\cline { 2 - 10 } & GF-R1-zinc & GF-R2-zinc & GF-R3-zinc & GC-R1 & GC-R2 & LF-R1-Instron & LF-R1-MTS250 & LC-R1 & LC-R2 \\
\hline$E(\mathrm{GPa})$ & 202.4 & 214.5 & 208.3 & 226.1 & 242.6 & 199.7 & 207.9 & 212.3 & 205.9 \\
$\sigma_{p}(\mathrm{MPa})$ & 249.7 & 311.8 & 360.2 & 240.6 & 200.2 & 310.0 & 220.2 & 441.6 & 337.1 \\
$\varepsilon_{p}(\%)$ & 0.12 & 0.15 & 0.17 & 0.11 & 0.08 & 0.16 & 0.11 & 0.21 & 0.16 \\
$\sigma_{0.2}(\mathrm{MPa})$ & 454.8 & 490.4 & 483.1 & 541.2 & 566.9 & 639.2 & 626.1 & 892.7 & 861.3 \\
$\varepsilon_{0.2}(\%)$ & 0.42 & 0.43 & 0.43 & 0.44 & 0.42 & 0.51 & 0.50 & 0.62 & 0.62 \\
$\sigma_{u}(\mathrm{MPa})$ & 482.6 & 517.1 & 504.2 & 573.5 & 598.3 & 732.7 & 725.1 & 1004.9 & 989.3 \\
$\varepsilon_{u}(\%)$ & 5.7 & 7.5 & 6.1 & 1.2 & 1.3 & 21.3 & 22.7 & 2.4 & 1.9 \\
$\varepsilon_{f}(\%)$ & 13.1 & 12.9 & 11.8 & 6.2 & 6.3 & 35.3 & 32.7 & 12.7 & 12.6 \\
$n$ & 14.0 & 19.8 & 25.9 & 5.7 & 5.3 & 12.5 & 5.3 & 5.8 & 4.8 \\
$\sigma_{u} / \sigma_{0.2}$ & 1.06 & 1.05 & 1.04 & 1.06 & 1.06 & 1.15 & 1.16 & 1.13 & 1.15 \\
\hline
\end{tabular}

Table 11: Summary of tensile coupon test results obtained from static curves 


\begin{tabular}{c|cc|ccc}
\hline \multirow{2}{*}{ Series } & Location of & Strain rate before static & \multicolumn{3}{|c}{ Stress reduction (\%) } \\
\cline { 4 - 6 } & static drop & drop $\times 10^{-3}\left(\mathrm{~min}^{-1}\right)$ & $60 \mathrm{~s}$ & $100 \mathrm{~s}$ & $300 \mathrm{~s}$ \\
\hline \multirow{3}{*}{ GF-S } & Yield & 0.3 & -3.1 & -3.4 & -4.0 \\
& Ultimate & 0.3 & -2.8 & -3.1 & -4.1 \\
& Ultimate\# & 3.8 & -3.7 & -4.3 & -4.9 \\
\hline \multirow{4}{*}{ GF-R } & Plastic & 0.3 & -0.6 & -0.7 & -1.5 \\
& Yield & 3.8 & -3.6 & -4.0 & -4.8 \\
& Ultimate & 3.8 & -3.8 & -4.2 & -4.8 \\
\hline \multirow{2}{*}{ GF-L } & Yield & 5 & -3.7 & -4.7 & -6.6 \\
& Ultimate & 45 & -5.8 & -6.0 & -7.2 \\
\hline \multirow{2}{*}{ GF-U } & Yield & 30 & -6.8 & -7.4 & -9.3 \\
& Ultimate & 460 & -7.8 & -8.1 & -8.9 \\
\hline \multirow{3}{*}{ GC-R } & Plastic & 0.2 & -3.2 & -3.2 & -3.3 \\
& Yield & 2.5 & -3.8 & -4.2 & -4.7 \\
& Ultimate & 2.5 & -4.0 & -4.3 & -4.6 \\
\hline
\end{tabular}

Table 12: Average stress reduction during stress relaxation for cold-formed carbon steel G450 at different strain rate series as shown in Table 2

\begin{tabular}{c|cc|ccc}
\hline \multirow{2}{*}{ Series } & Location of & Strain rate before static & \multicolumn{3}{|c}{ Stress reduction (\%) } \\
\cline { 4 - 6 } & static drop & drop $\times 10^{-3}\left(\mathrm{~min}^{-1}\right)$ & $60 \mathrm{~s}$ & $100 \mathrm{~s}$ & $300 \mathrm{~s}$ \\
\hline \multirow{4}{*}{ LF-R } & Plastic & 0.3 & -2.2 & -2.6 & -3.5 \\
& Yield & 13 & -6.3 & -6.5 & -7.7 \\
& Ultimate & 13 & -6.0 & -6.4 & -7.5 \\
& Ultimate\# & 35 & -7.0 & -7.4 & -8.1 \\
\hline \multirow{2}{*}{ LF-L } & Yield & 6 & -6.0 & -6.7 & -7.7 \\
& Ultimate & 44 & -7.4 & -7.7 & -8.0 \\
\hline \multirow{2}{*}{ LF-U } & Yield & 20 & -7.4 & -8.6 & -9.3 \\
& Ultimate & 440 & -10.8 & -10.9 & -10.9 \\
\hline \multirow{3}{*}{ LC-R } & Plastic & 0.2 & -2.7 & -2.8 & -2.9 \\
& Yield & 28 & -5.3 & -5.4 & -6.3 \\
& Ultimate & 28 & -5.5 & -5.9 & -6.3 \\
\hline
\end{tabular}

Table 13: Average stress reduction during stress relaxation for cold-formed lean duplex stainless steel at different strain rate series as shown in Table 2

\begin{tabular}{c|cc|ccc}
\hline \multirow{2}{*}{ Series } & Location of & Strain rate before static & \multicolumn{3}{|c}{ Stress reduction (\%) } \\
\cline { 4 - 6 } & static drop & drop $\times 10^{-3}\left(\mathrm{~min}^{-1}\right)$ & $60 \mathrm{~s}$ & $100 \mathrm{~s}$ & $300 \mathrm{~s}$ \\
\hline \multirow{2}{*}{ FF-S } & Yield & 0.3 & -4.2 & -4.8 & -5.3 \\
& Ultimate & 7 & -3.7 & -4.3 & -5.4 \\
\hline \multirow{2}{*}{ FF-R } & Yield & 13 & -4.7 & -5.2 & -6.4 \\
& Ultimate & 13 & -4.7 & -5.1 & -6.0 \\
\hline \multirow{2}{*}{ FF-L } & Yield & 8 & -5.3 & -5.6 & -6.2 \\
& Ultimate & 50 & -6.2 & -7.0 & -7.3 \\
\hline \multirow{2}{*}{ FF-U } & Yield & 25 & -5.6 & -6.2 & -7.2 \\
& Ultimate & 490 & -9.8 & -9.9 & -9.9 \\
\hline
\end{tabular}

Table 14: Average stress reduction during stress relaxation for cold-formed ferritic stainless steel at different strain rate series as shown in Table 2 


\begin{tabular}{c|cc|ccc}
\hline \multirow{2}{*}{ Series } & Location of & Strain rate before static & \multicolumn{3}{|c}{ Stress reduction (\%) } \\
\cline { 4 - 6 } & static drop & drop $\times 10^{-3}\left(\mathrm{~min}^{-1}\right)$ & $60 \mathrm{~s}$ & $100 \mathrm{~s}$ & $300 \mathrm{~s}$ \\
\hline \multirow{3}{*}{ AF-R } & Plastic & 0.4 & -1.3 & -1.5 & -1.5 \\
& Yield & 7 & -2.7 & -2.9 & -3.2 \\
& Ultimate & 7 & -3.6 & -4.0 & -5.3 \\
\hline \multirow{2}{*}{ AF-L } & Yield & 12 & -2.0 & -2.0 & -2.3 \\
& Ultimate & 50 & -4.9 & -5.4 & -6.6 \\
\hline \multirow{2}{*}{ AF-U } & Yield & 25 & -3.8 & -4.0 & -4.0 \\
& Ultimate & 400 & -6.5 & -7.2 & -7.5 \\
\hline
\end{tabular}

Table 15: Average stress reduction during stress relaxation for aluminium alloy at different strain rate series as shown in Table 2

\begin{tabular}{|c|c|c|c|c|c|c|}
\hline \multirow{3}{*}{ Specimen } & \multicolumn{6}{|c|}{ Young’s Modulus E (GPa) } \\
\hline & \multicolumn{3}{|c|}{ Strain gauge } & \multicolumn{3}{|c|}{ Extensometer } \\
\hline & $\begin{array}{l}\text { Linear } \\
\text { portion }\end{array}$ & $\begin{array}{l}\text { Unloading } \\
\text {-reloading }\end{array}$ & $\begin{array}{l}\text { Slope between } \\
\text { two points }\end{array}$ & $\begin{array}{l}\text { Linear } \\
\text { portion }\end{array}$ & $\begin{array}{l}\text { Unloading } \\
\text {-reloading }\end{array}$ & $\begin{array}{l}\text { Slope between } \\
\text { two points }\end{array}$ \\
\hline GF-S1 & 217.9 & --- & 187.5 & 216.9 & --- & 187.8 \\
\hline GF-S2 & 214.5 & 211.1 & 190.2 & 217.8 & 217.5 & 187.2 \\
\hline GF-S3 & 216.7 & 214.4 & 193.8 & 226.9 & 209.9 & 195.0 \\
\hline GF-R1 & 213.9 & --- & 187.9 & 212.4 & --- & 188.7 \\
\hline GF-R2 & 219.0 & 216.6 & 194.1 & 210.6 & 211.8 & 195.3 \\
\hline GF-R3 & 218.6 & 215.5 & 195.1 & 215.2 & 208.1 & 196.4 \\
\hline GF-R1-zinc & 202.4 & --- & 176.8 & 203.6 & --- & 175.6 \\
\hline GF-R2-zinc & 214.5 & 212.0 & 191.6 & 204.8 & 204.2 & 192.8 \\
\hline GF-R3-zinc & 208.3 & 208.0 & 185.5 & 201.0 & 217.1 & 183.7 \\
\hline GF-L1 & 227.0 & 216.7 & 199.1 & 228.2 & 225.6 & 199.6 \\
\hline GF-L2 & 218.7 & 217.5 & 194.9 & 225.3 & 212.0 & 195.5 \\
\hline GF-L3 & 220.6 & 215.8 & 198.5 & 238.8 & 223.4 & 200.6 \\
\hline GF-U1 & 221.5 & 209.5 & 196.8 & 214.5 & 219.0 & 196.6 \\
\hline GF-U2 & 221.0 & 220.4 & 197.4 & 225.3 & 227.8 & 195.3 \\
\hline GF-U3 & 218.5 & --- & 201.4 & 216.0 & --- & 192.3 \\
\hline GC-R1 & 226.1 & --- & 176.5 & 295.6 & --- & 188.1 \\
\hline GC-R2 & 247.5 & 241.3 & 185.7 & 358.3 & 316.2 & 196.3 \\
\hline LF-R1 & 197.7 & --- & 184.3 & 231.9 & --- & 189.6 \\
\hline LF-R2 & 197.8 & 195.8 & 183.7 & 173.7 & 179.1 & 172.1 \\
\hline LF-L1 & 202.6 & 198.9 & 189.9 & 178.3 & 191.1 & 176.4 \\
\hline LF-L2 & 200.7 & 198.2 & 198.9 & 215.0 & 212.8 & 213.1 \\
\hline LF-U1 & 198.5 & --- & 188.7 & 183.9 & --- & 182.7 \\
\hline LF-U2 & 205.4 & 196.4 & 187.7 & 193.2 & 194.3 & 181.5 \\
\hline LF-R1-Instron & 199.7 & --- & 190.8 & 207.6 & --- & 197.4 \\
\hline LF-R1-MTS250 & 207.9 & --- & 192.3 & 206.0 & --- & 187.9 \\
\hline LC-R1 & 226.1 & --- & 176.5 & 294.6 & --- & 188.1 \\
\hline LC-R2 & 205.9 & 204.4 & 199.4 & 464.9 & 337.0 & 383.3 \\
\hline FF-S1 & 204.8 & 197.8 & 145.8 & 223.0 & 226.9 & 141.2 \\
\hline FF-S2 & 203.6 & 197.7 & 152.6 & 217.0 & 217.5 & 152.6 \\
\hline FF-S3 & 202.2 & 195.6 & 143.4 & 213.7 & 223.1 & 141.9 \\
\hline FF-R1 & 211.4 & 205.3 & 159.2 & 229.8 & 215.2 & 153.7 \\
\hline FF-R2 & 204.6 & 200.0 & 148.2 & 235.9 & 220.7 & 154.1 \\
\hline
\end{tabular}




\begin{tabular}{l|ccc|ccc} 
FF-R3 & 202.1 & 195.6 & 159.6 & 205.3 & 223.1 & 161.4 \\
FF-L1 & 211.6 & 197.8 & 105.6 & 241.4 & 225.6 & 101.3 \\
FF-L2 & 211.2 & 202.1 & 152.1 & 225.5 & 233.6 & 150.7 \\
FF-L3 & 206.5 & 199.3 & 158.3 & 247.0 & 223.3 & 150.6 \\
FF-U1 & 212.4 & 193.2 & 152.3 & 227.4 & 219.7 & 153.7 \\
FF-U2 & 206.9 & 197.8 & 151.3 & 232.1 & 233.0 & 154.4 \\
FF-U3 & 205.5 & 198.5 & 150.7 & 236.6 & 235.4 & 146.2 \\
\hline AF-R1 & 67.3 & --- & 65.4 & 67.0 & --- & 64.7 \\
AF-R2 & 66.4 & --- & 63.5 & 66.3 & --- & 64.5 \\
AF-R3 & 67.0 & 66.9 & 64.4 & 67.4 & 66.9 & 64.0 \\
AF-L1 & 66.7 & 64.9 & 65.0 & 67.6 & 64.6 & 63.9 \\
AF-L2 & 71.0 & 69.8 & 71.0 & 67.9 & 64.2 & 61.5 \\
AF-L3 & 66.3 & 65.2 & 61.8 & 66.9 & 65.6 & 62.3 \\
AF-U1 & 66.4 & --- & 63.6 & 64.0 & --- & 64.5 \\
AF-U2 & 66.7 & 65.5 & 65.4 & 67.7 & 65.3 & 60.2 \\
AF-U3 & 66.0 & 65.8 & 65.3 & 65.9 & 66.5 & 63.6 \\
\hline
\end{tabular}

Table 16: Summary of Young's modulus obtained from three methods and measured by strain gauge and extensometer

\begin{tabular}{c|cc|cc}
\hline & \multicolumn{2}{|c|}{ Flat coupon } & \multicolumn{2}{c}{ Curved coupon } \\
\cline { 2 - 5 } & Strain (\%) & $\begin{array}{c}\text { Loading rate } \\
(\mathrm{mm} / \mathrm{min})\end{array}$ & Strain (\%) & $\begin{array}{c}\text { Loading rate } \\
\text { (mm/min) }\end{array}$ \\
\hline Relatively ductile material & $0-0.2$ & 0.05 & $\sim 0-0.15$ & 0.05 \\
with $\varepsilon_{f}=15 \%$ (flat coupon) & $0.2-0.6$ & 0.4 & $0.15-0.5$ & 0.4 \\
and $\varepsilon_{f}=7 \%$ (curved & 0.6 & paused $100 \mathrm{~s}$ & 0.5 & paused 100s \\
coupon) & $0.6-7.0$ & 0.4 & $0.5-1.5$ & 0.4 \\
(e.g. cold-formed carbon & 7.0 & paused 100s & 1.5 & paused 100s \\
steel) & $7.0-$ fracture & 0.8 & $1.5-$ fracture & 0.4 \\
\hline Ductile material & $0-0.2$ & 0.05 & $\sim 0-0.15$ & 0.05 \\
with $\varepsilon_{f}=40 \%$ (flat coupon) & $0.2-0.6$ & 0.8 & $0.15-0.5$ & 0.8 \\
and $\varepsilon_{f}=15 \%$ (curved & 0.6 & paused 100s & 0.5 & paused 100s \\
coupon) & $0.6-20.0$ & 0.8 & $0.5-2.5$ & 0.8 \\
(e.g. cold-formed stainless & 20.0 & paused 100s & 2.5 & paused 100s \\
steel) & $20.0-$ fracture & 2 & $2.5-$ fracture & 0.8 \\
\hline & $0-0.2$ & 0.05 & & \\
Less ductile material & $0.2-0.6$ & 0.4 & & \\
with $\varepsilon_{f}=9 \%$ at flat portion & 0.6 & paused 100s & & \\
(e.g. aluminium alloy) & $0.6-6.0$ & 0.4 & & \\
& 6.0 & paused 100s & & \\
\hline & $6.0-$ fracture & 0.8 & & \\
\hline
\end{tabular}

Table 17: Loading procedure and loading rate of coupon specimens 


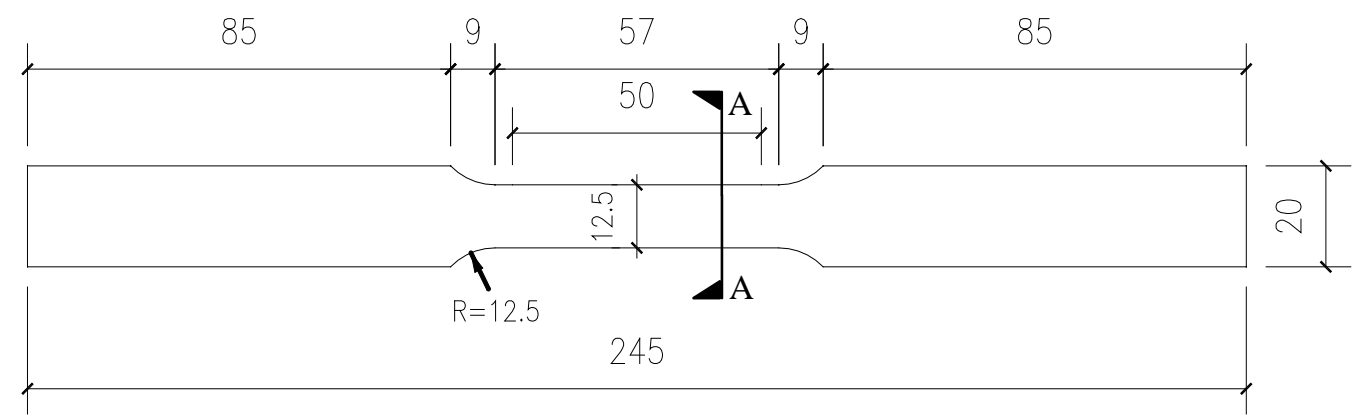

(a) Dimension of flat coupon

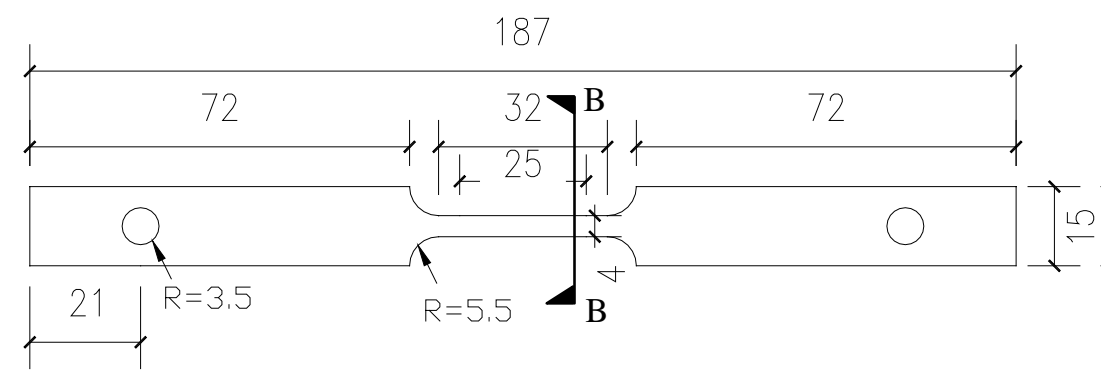

(b) Dimension of curved coupon

Fig 1: Dimension of coupon specimens

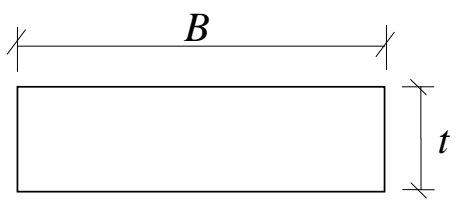

$\underline{\mathrm{A}-\mathrm{A}}$

(a) Definition for symbols of cross-sectional dimensions in flat coupon specimens

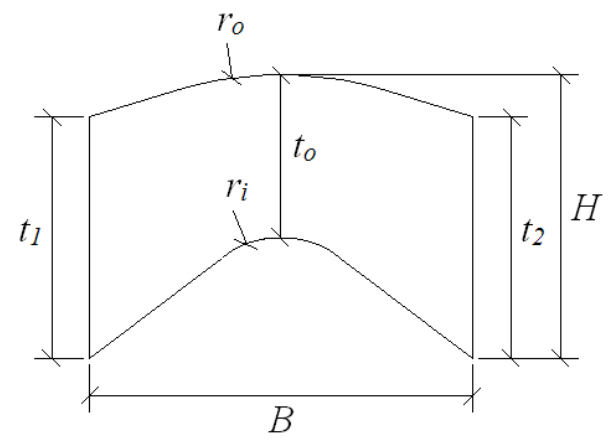

$\underline{\mathrm{B}-\mathrm{B}}$

(b) Definition for symbols of cross-sectional dimensions in curved coupon specimens Fig 2: Definition of symbols for the coupon specimens 


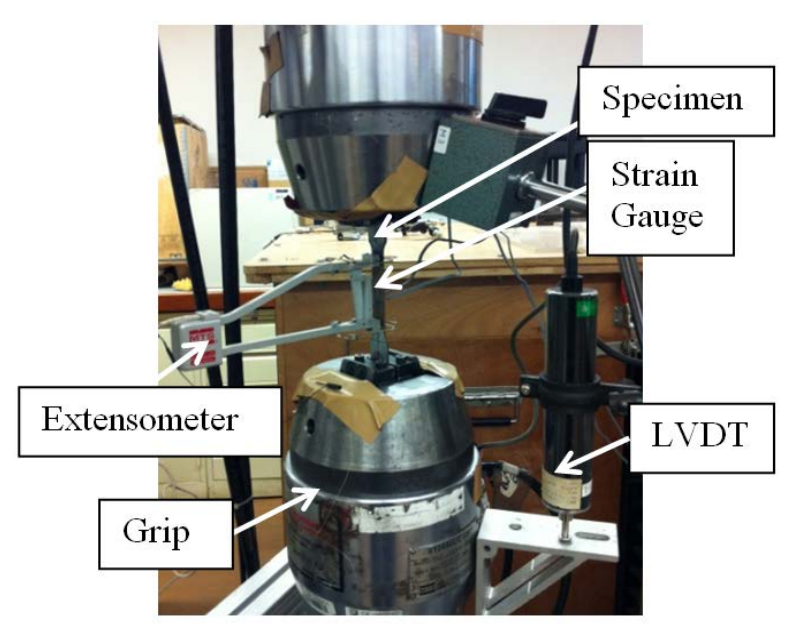

(a)

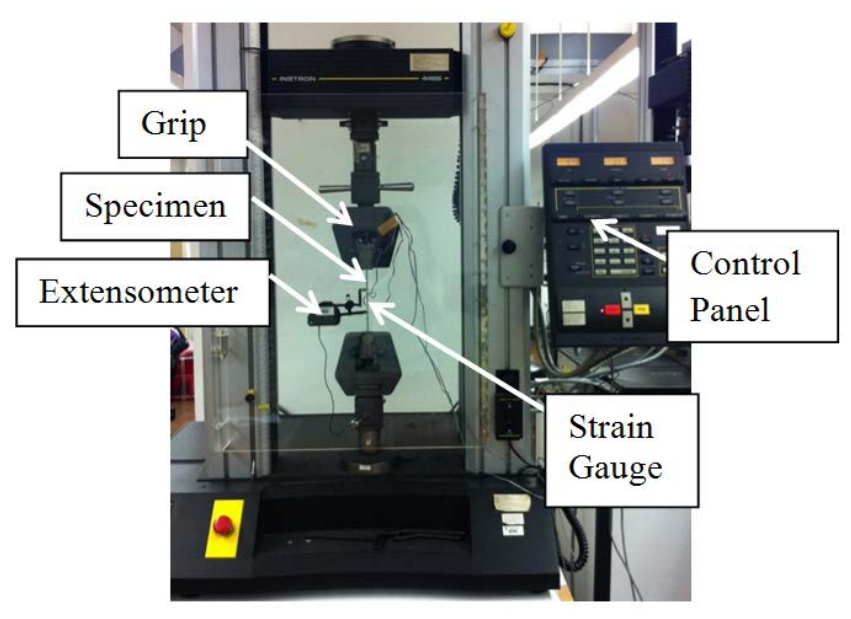

(c)

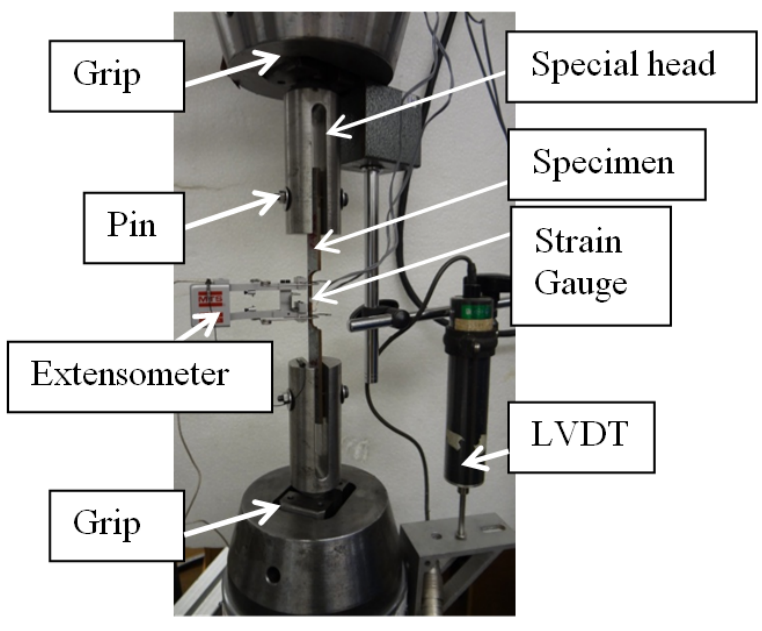

(b)

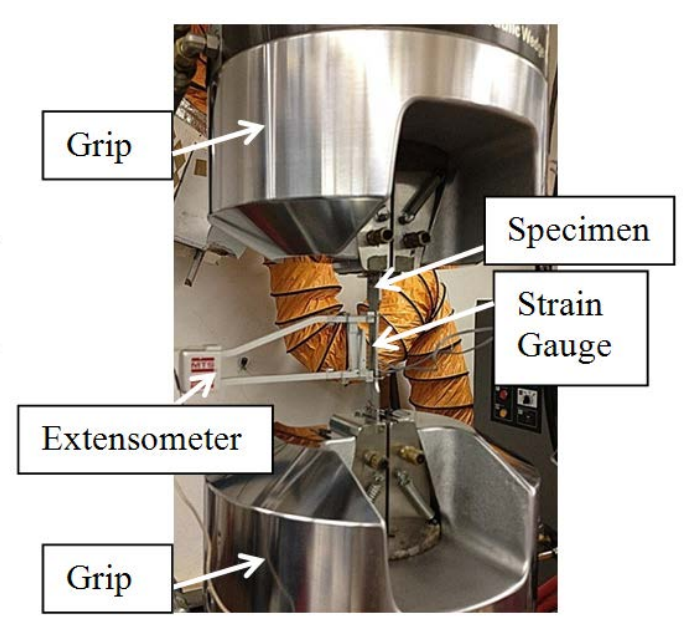

(d)

Fig 3: Test set-up used in this study (a) flat coupon tested by MTS 50kN, (b) curved coupon tested by MTS $50 \mathrm{kN}$, (c) flat coupon tested by Instron 4469, (d) flat coupon tested by MTS $250 \mathrm{kN}$ 


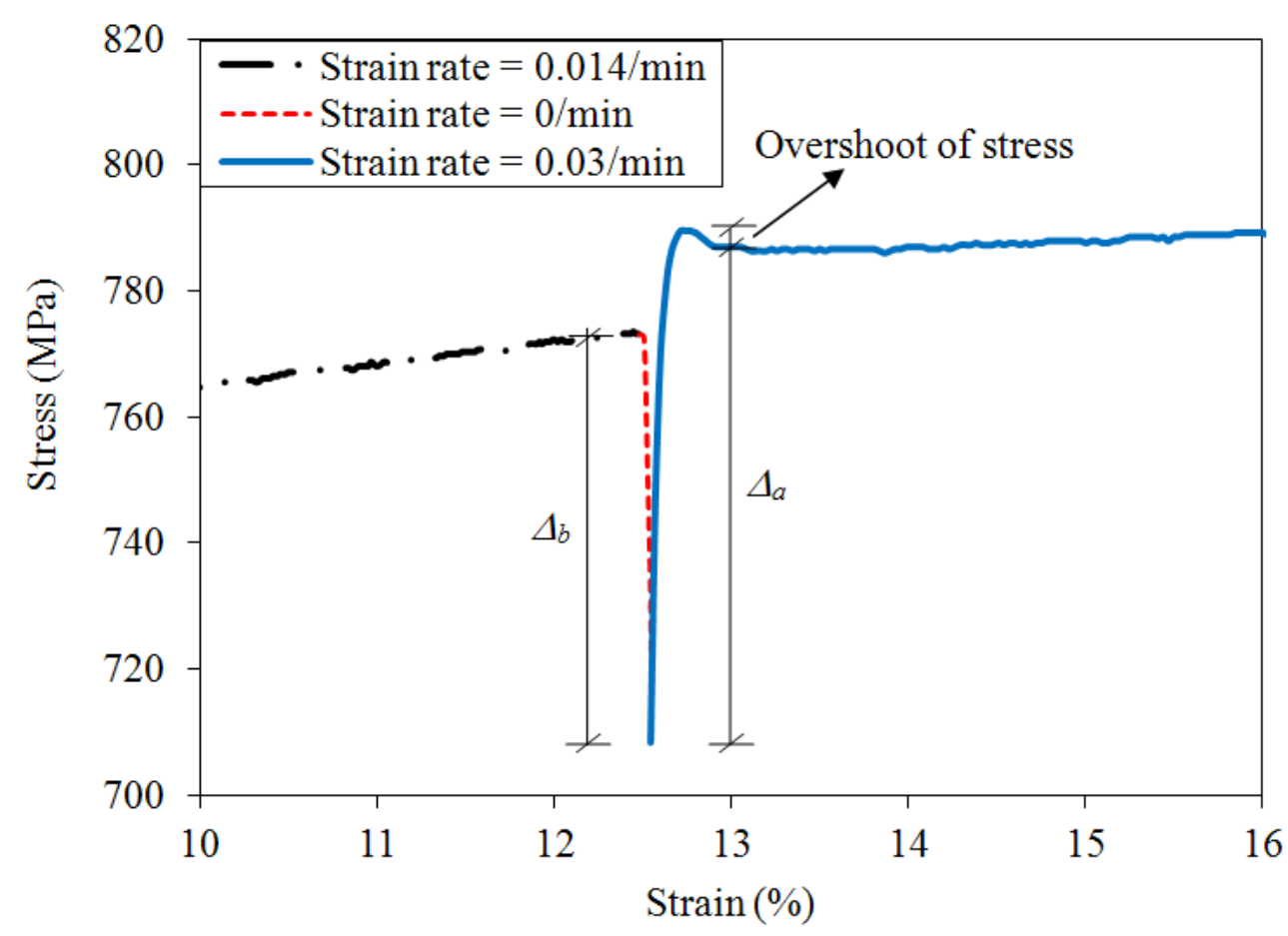

Fig 4: Typical static drop during stress relaxation in stress-strain curve

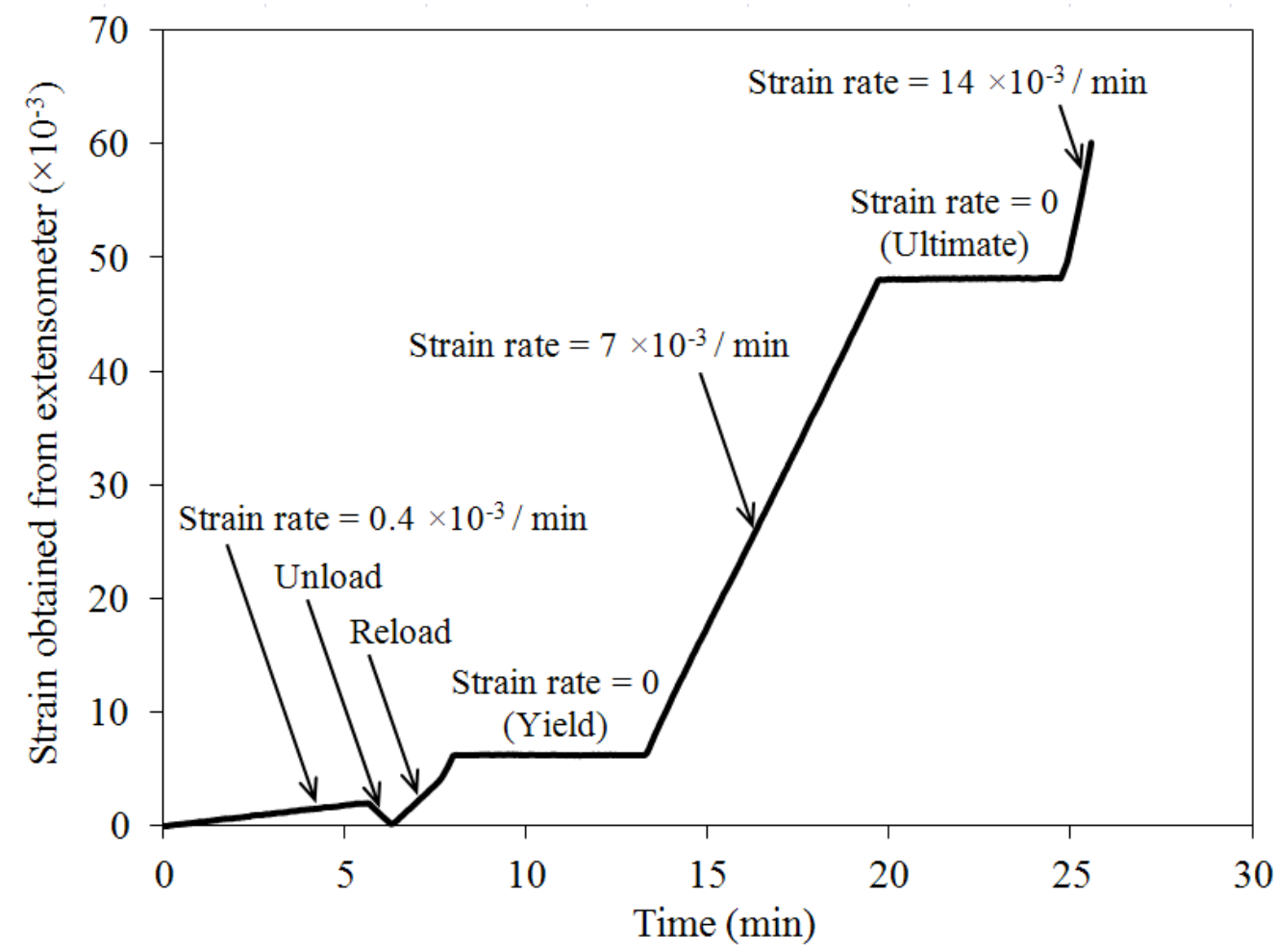

Fig 5: Loading history of specimen AF-R3 


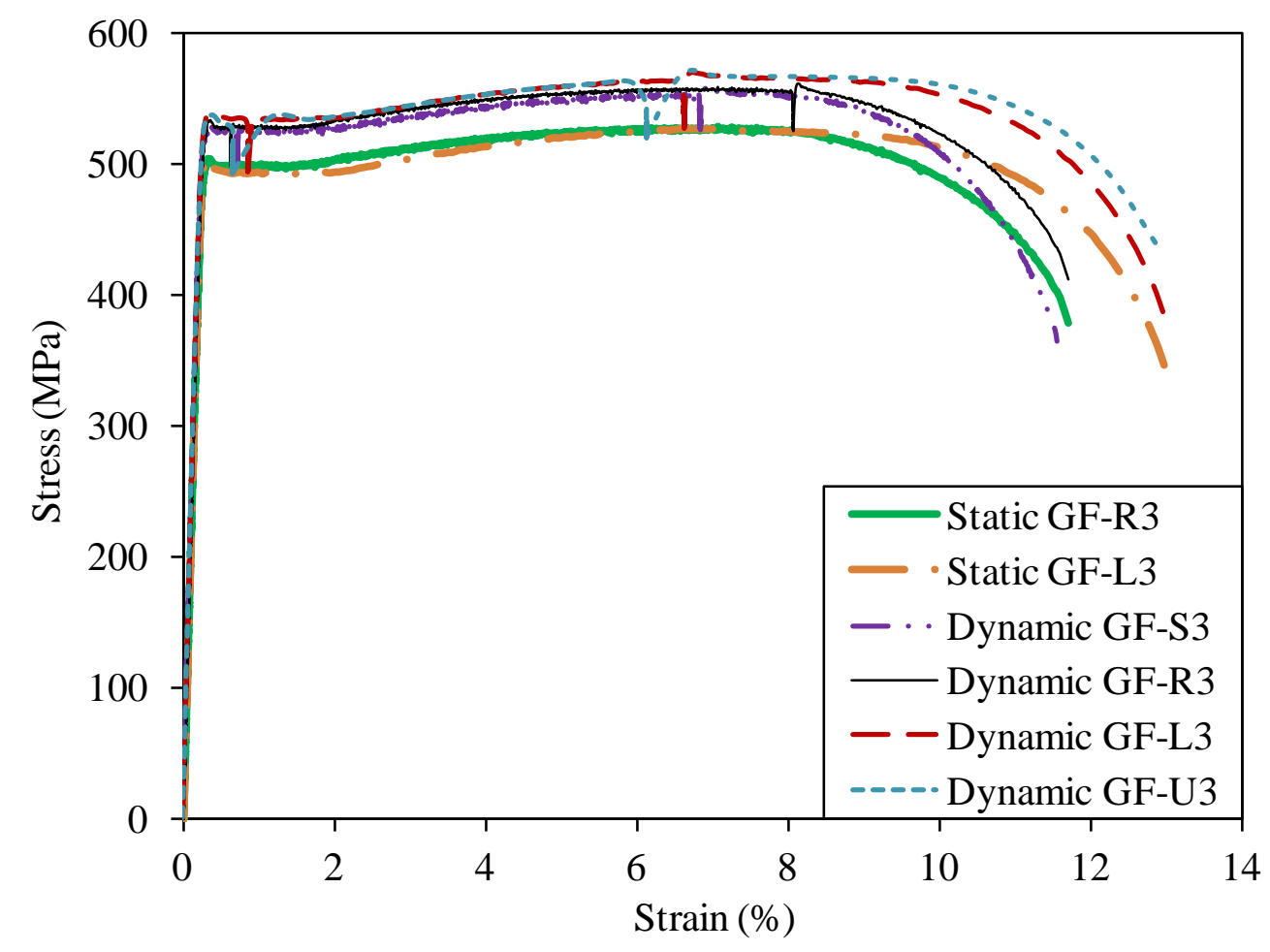

Fig 6: Summary of stress-strain curves for cold-formed carbon steel G450 under different loading rates as shown in Table 2

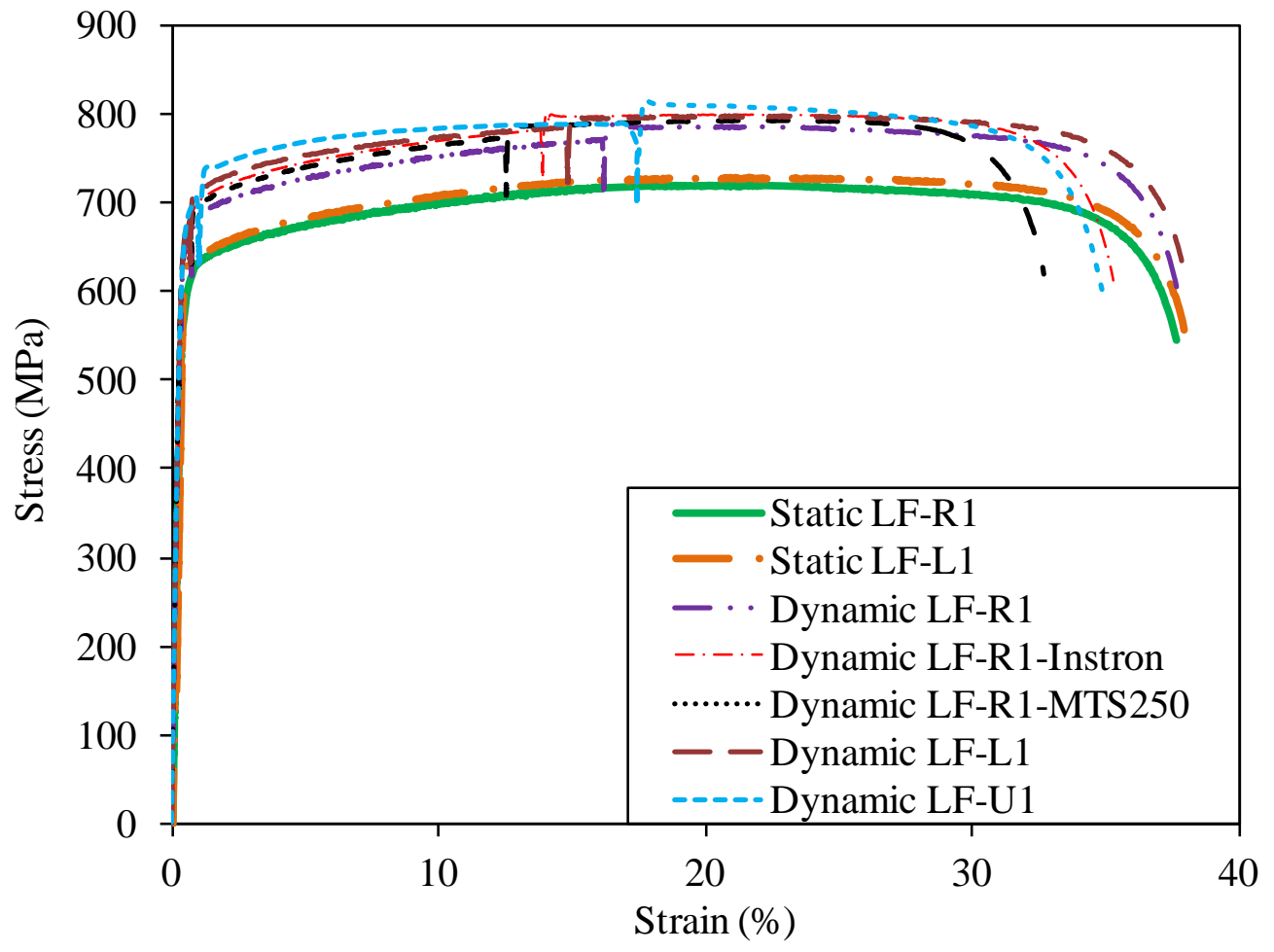

Fig 7: Summary of stress-strain curves for cold-formed lean duplex stainless steel under different loading rates as shown in Table 2 


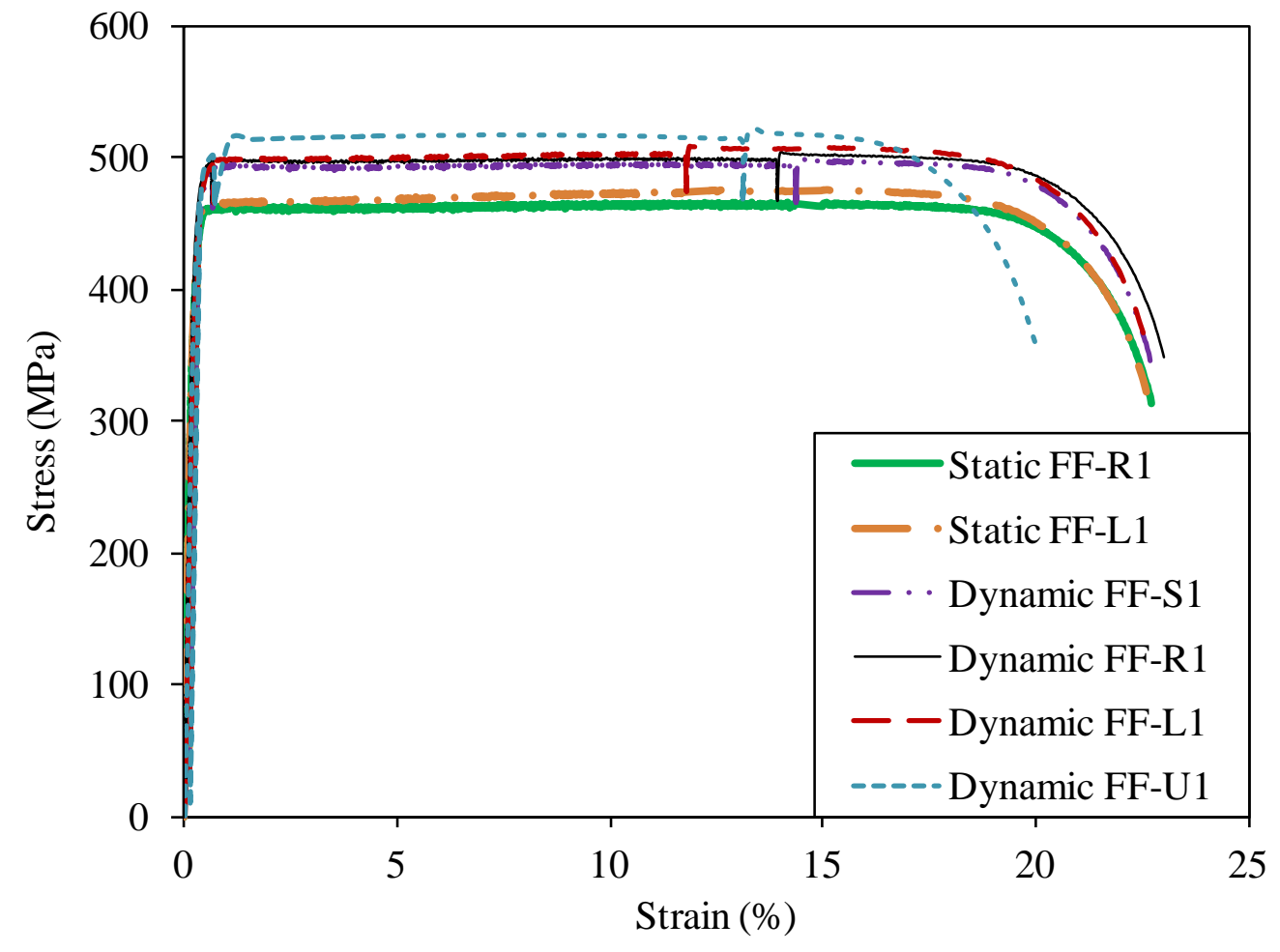

Fig 8: Summary of stress-strain curves for cold-formed ferritic stainless steel under different loading rates as shown in Table 2

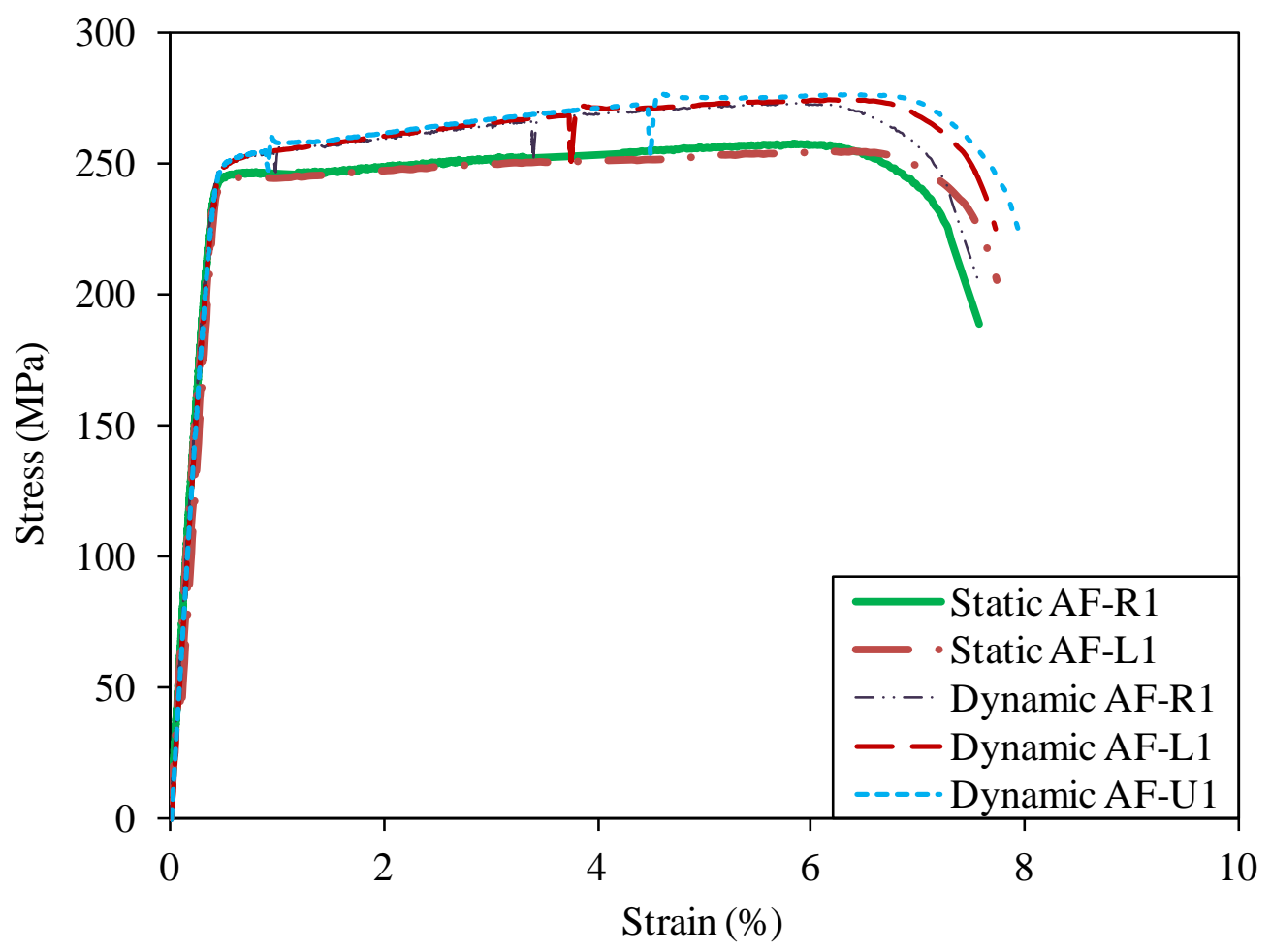

Fig 9: Summary of stress-strain curves for aluminium T6 alloy under different loading rates as shown in Table 2 


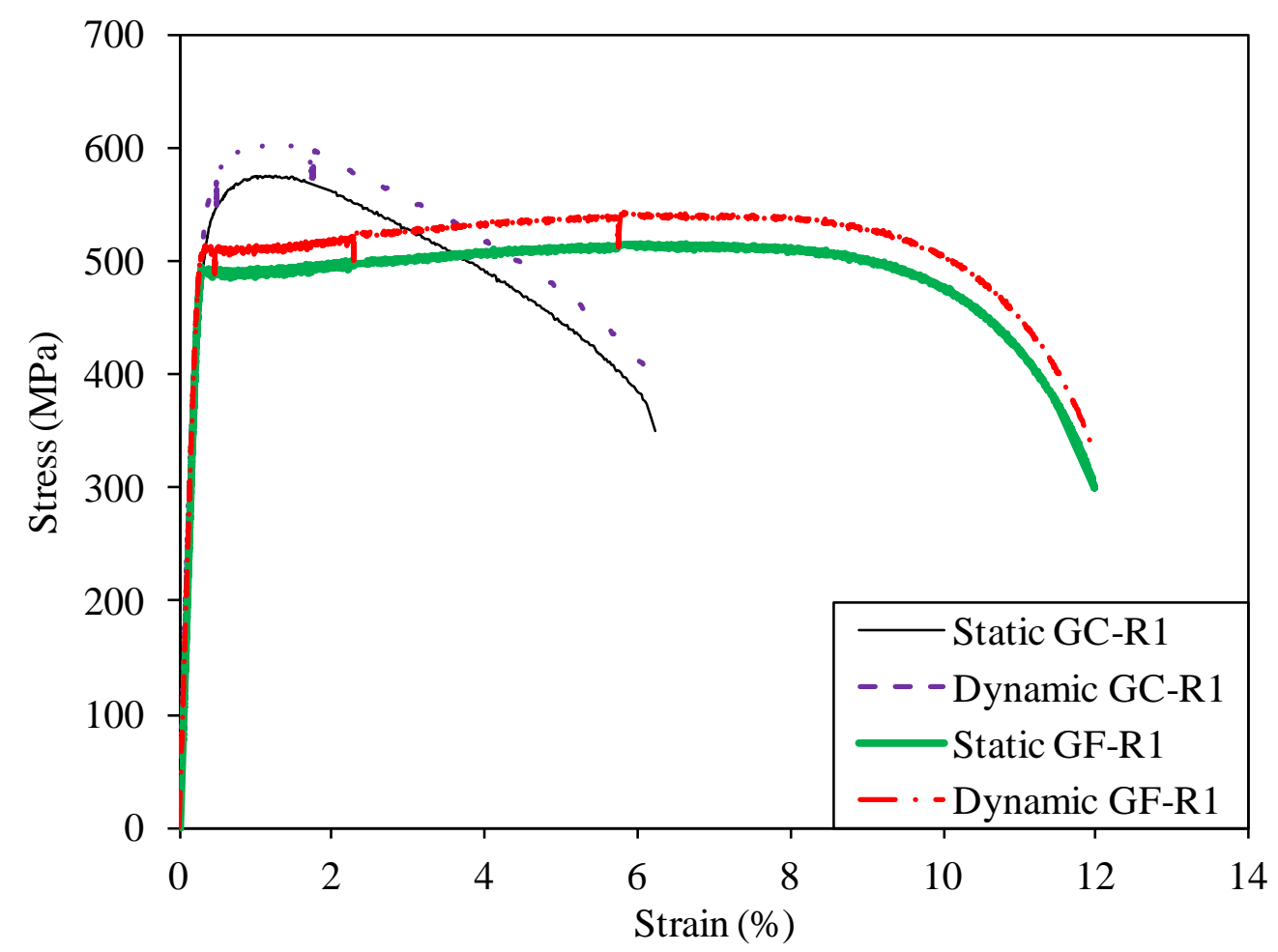

Fig 10: Dynamic and static stress-strain curves of flat and curved coupons of cold-formed carbon steel G450

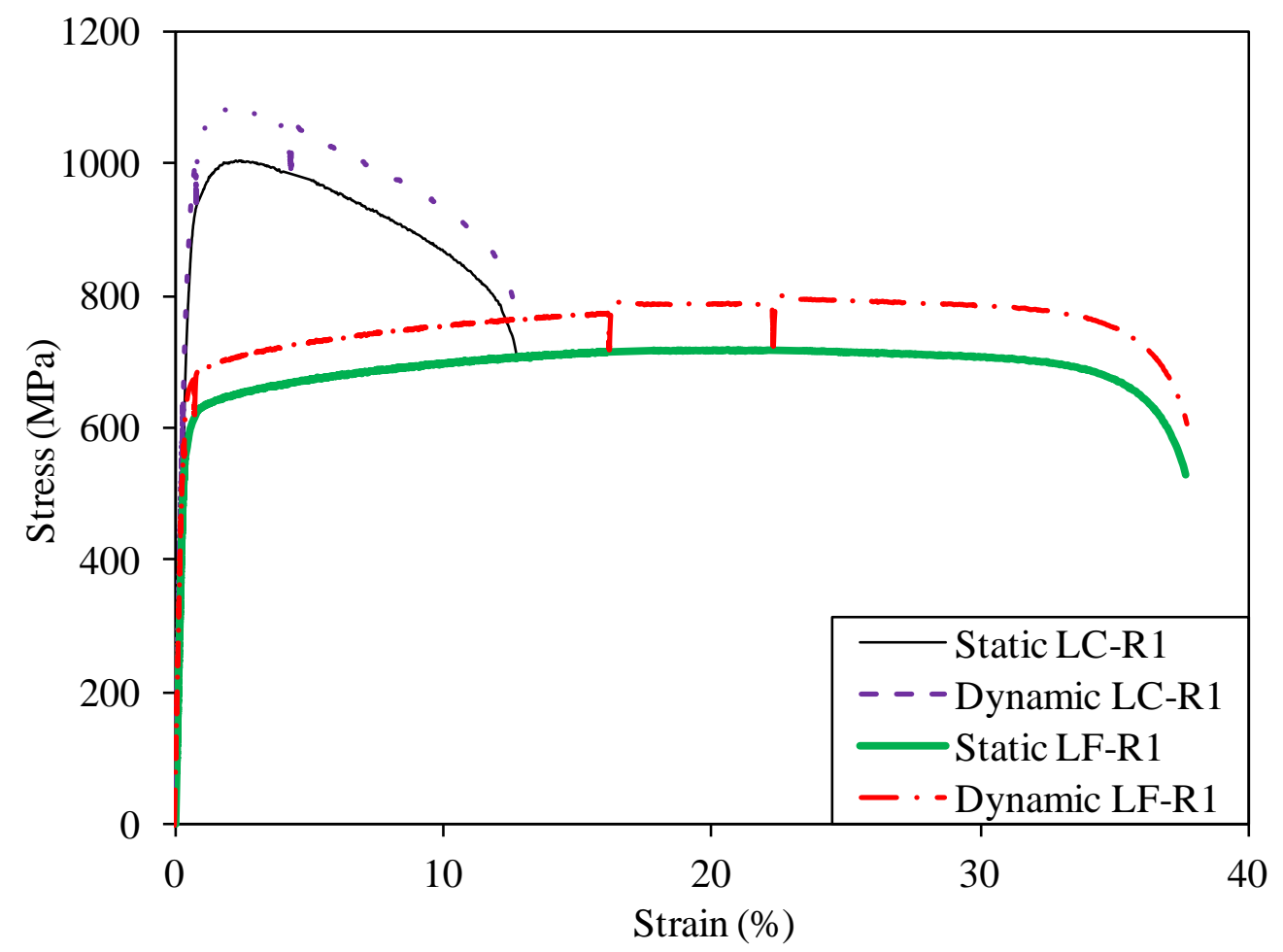

Fig 11: Dynamic and static stress-strain curves of flat and curved coupons of cold-formed lean duplex stainless steel 


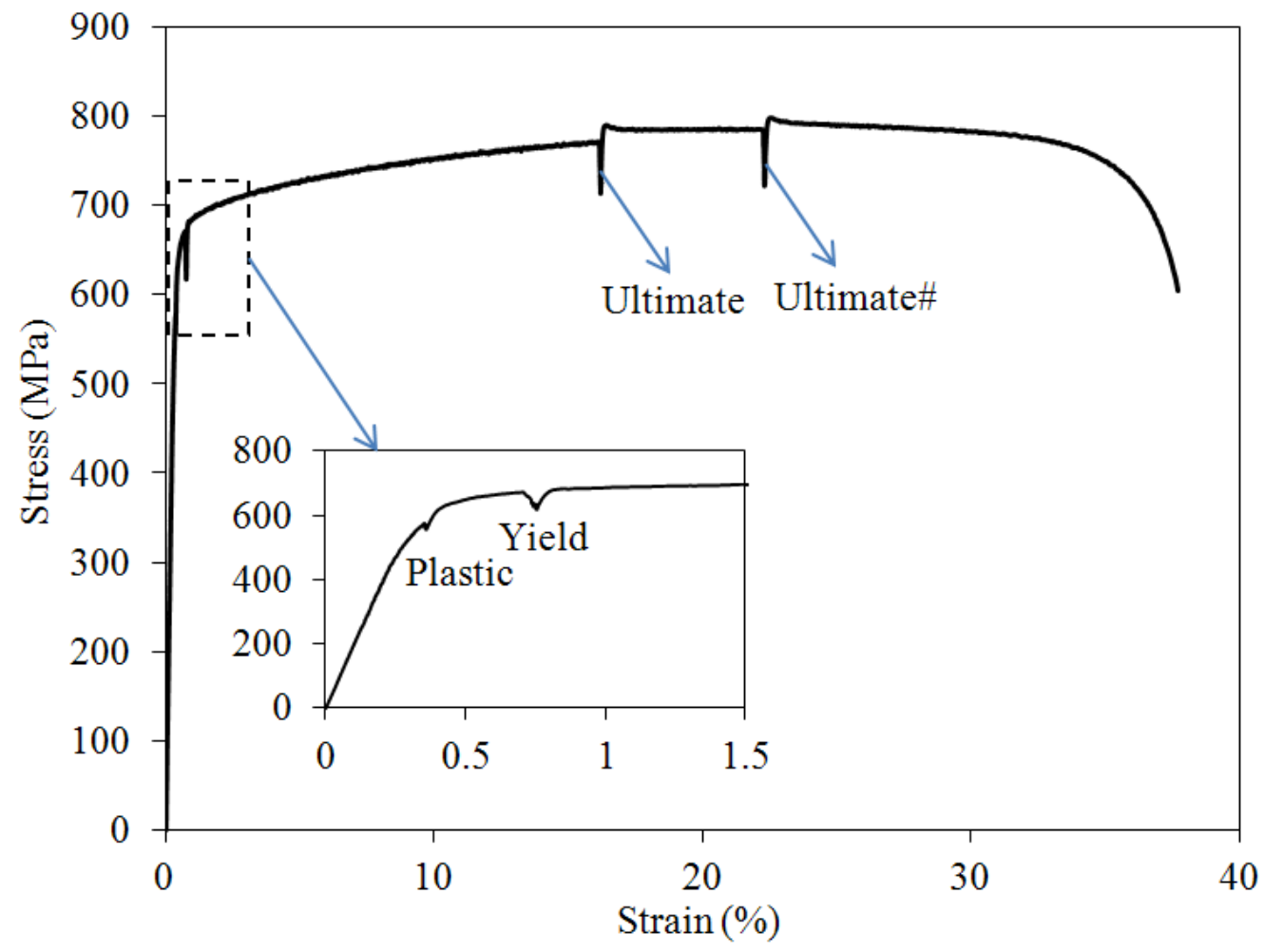

Fig 12: Location of static drops on stress-strain curve

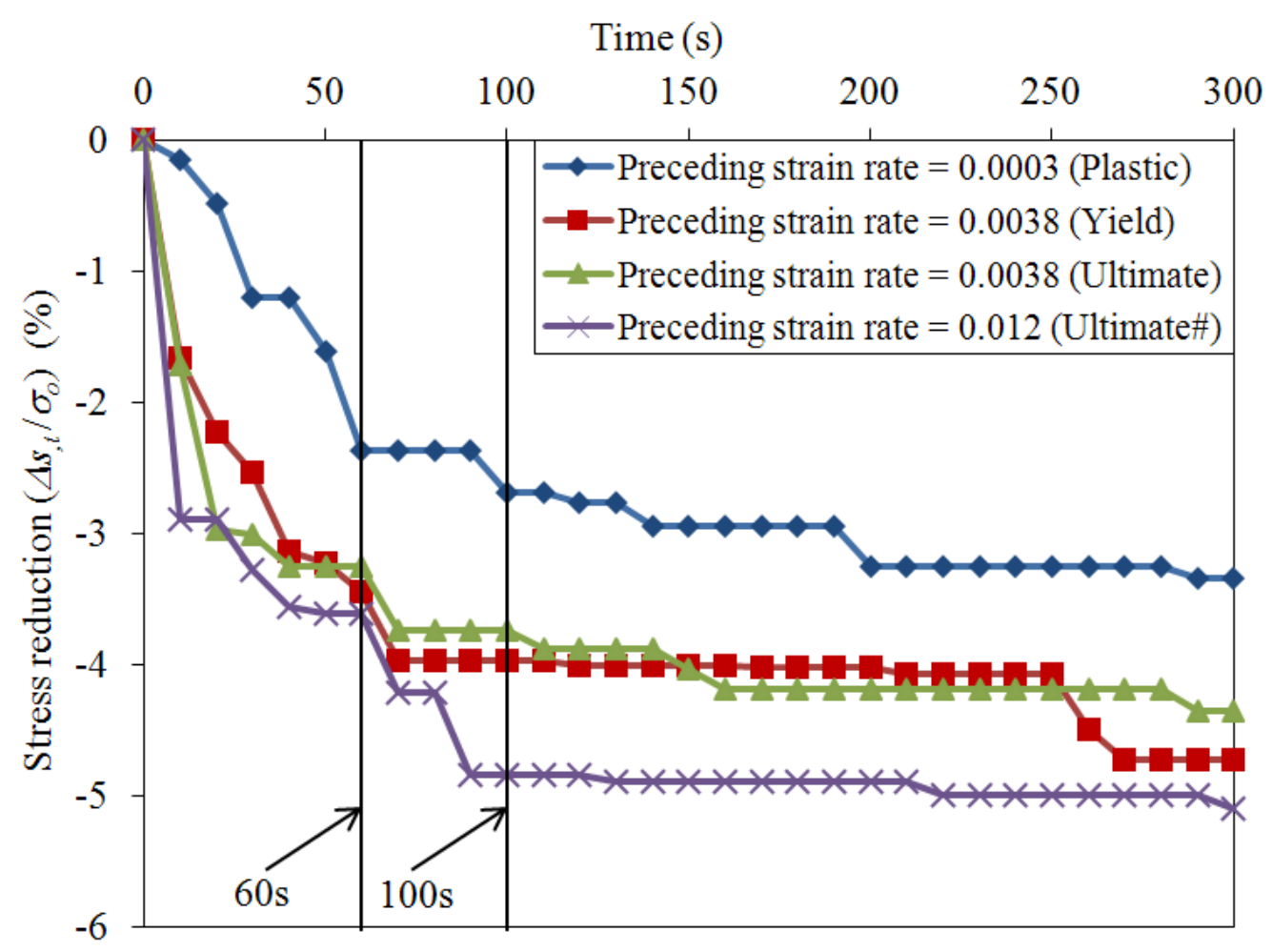

Fig 13: Stress relaxation with time for specimen GF-R1-zinc 


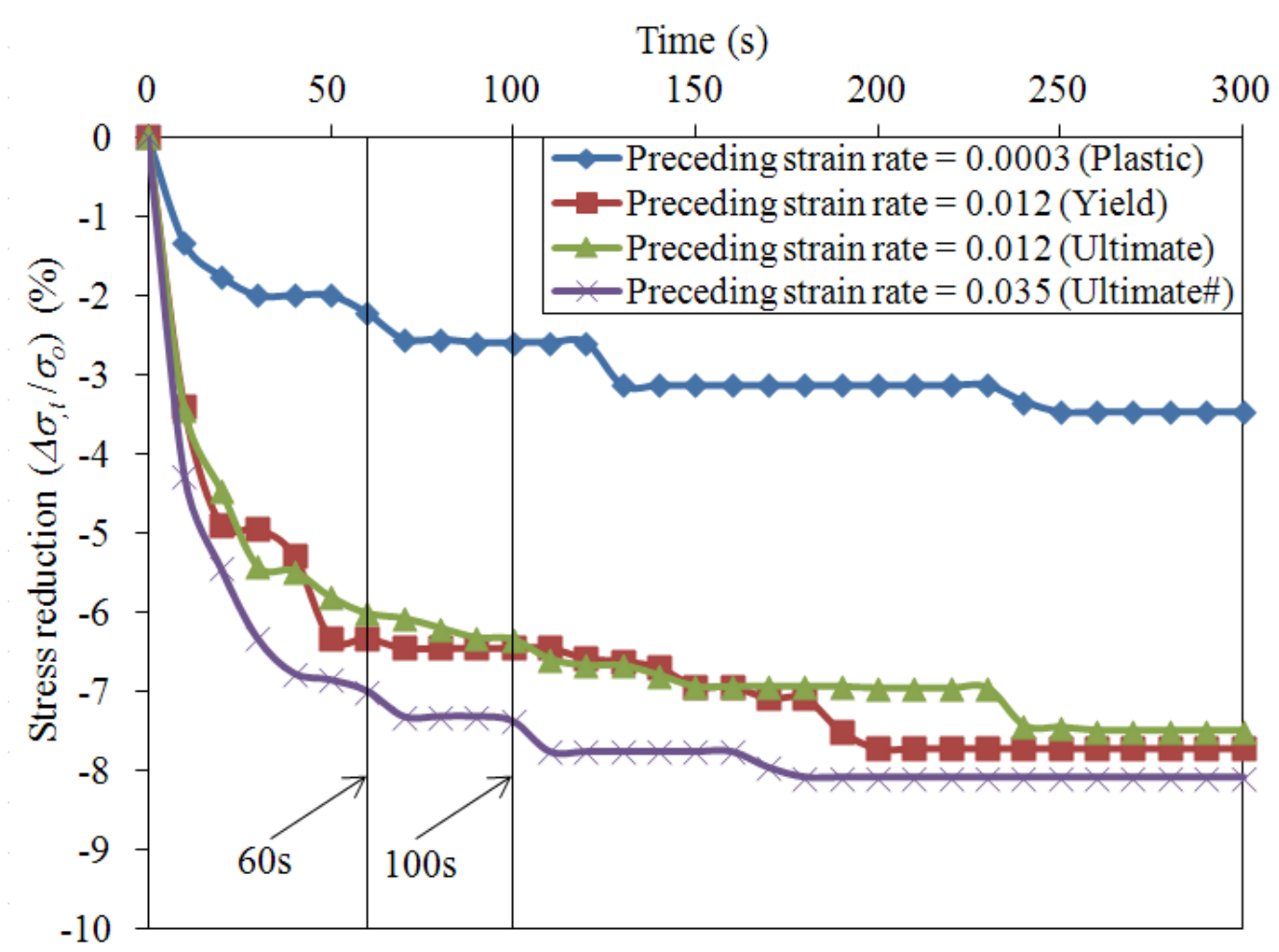

Fig 14: Stress relaxation with time for specimen LF-R1

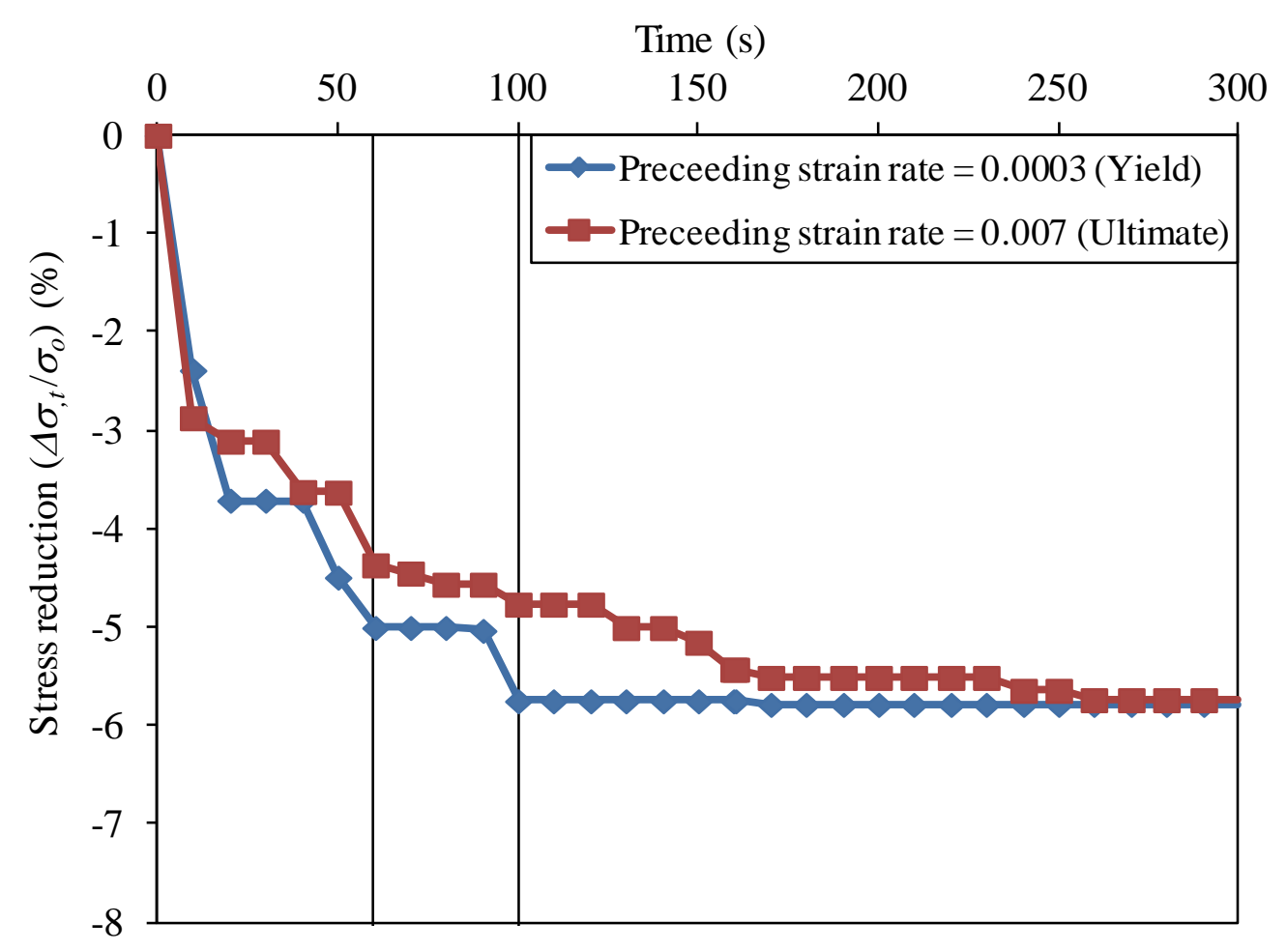

Fig 15: Stress relaxation with time for specimen FF-S1 


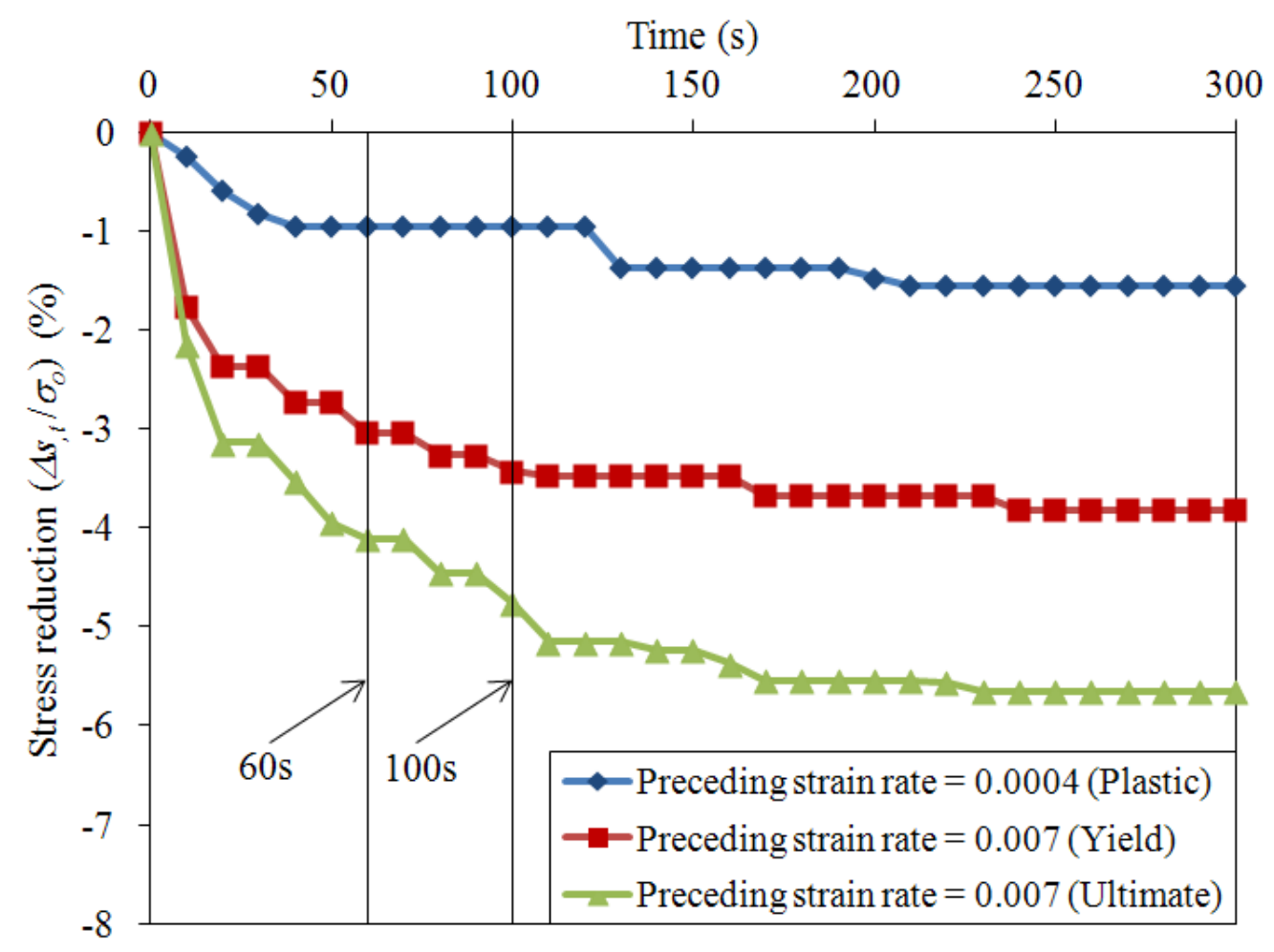

Fig 16: Stress relaxation with time for specimen AF-R1

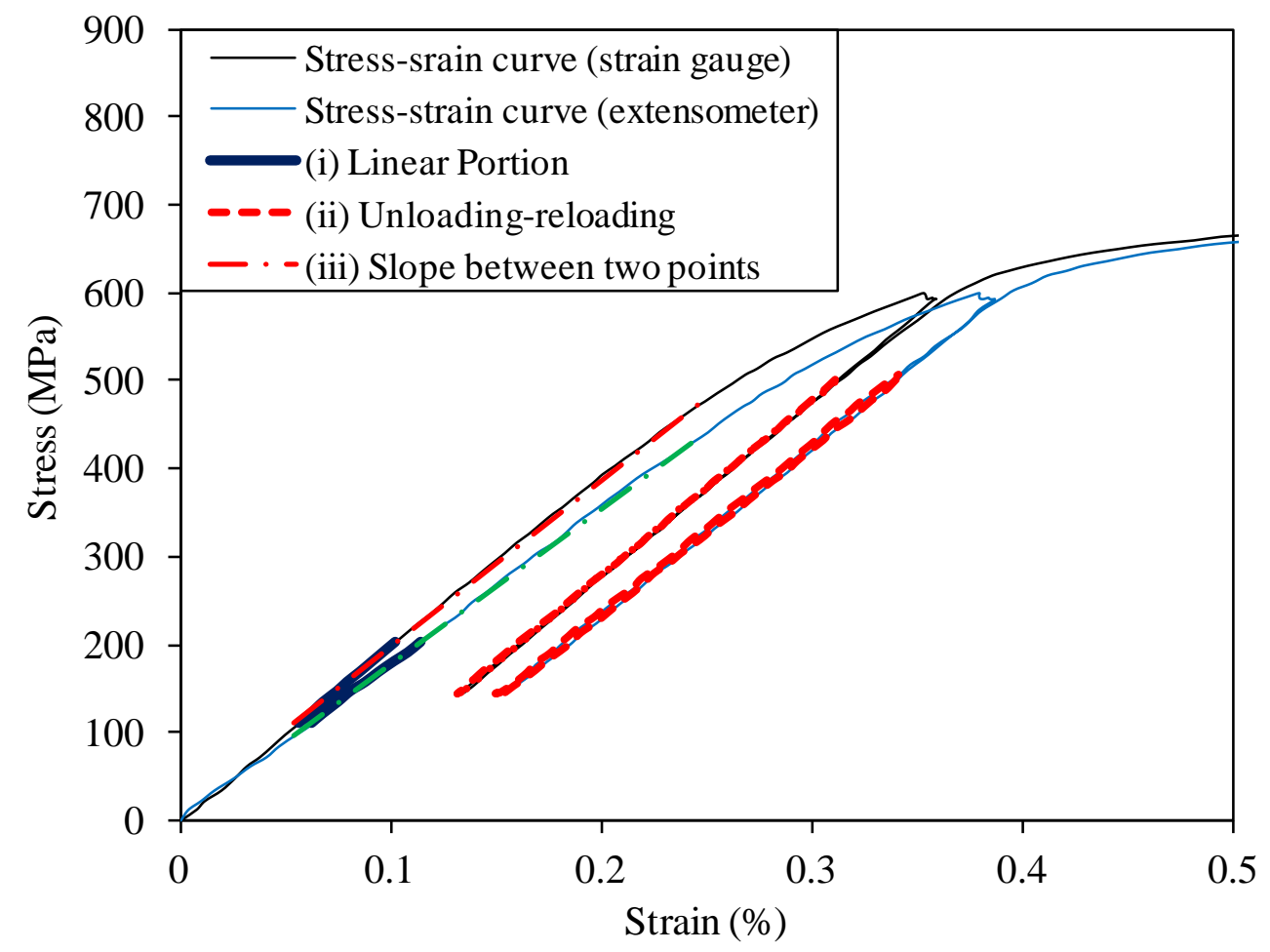

Fig 17: The three methods to obtain the Young’s modulus for specimen LF-L1 using strain gauge and extensometer in strain measurement 


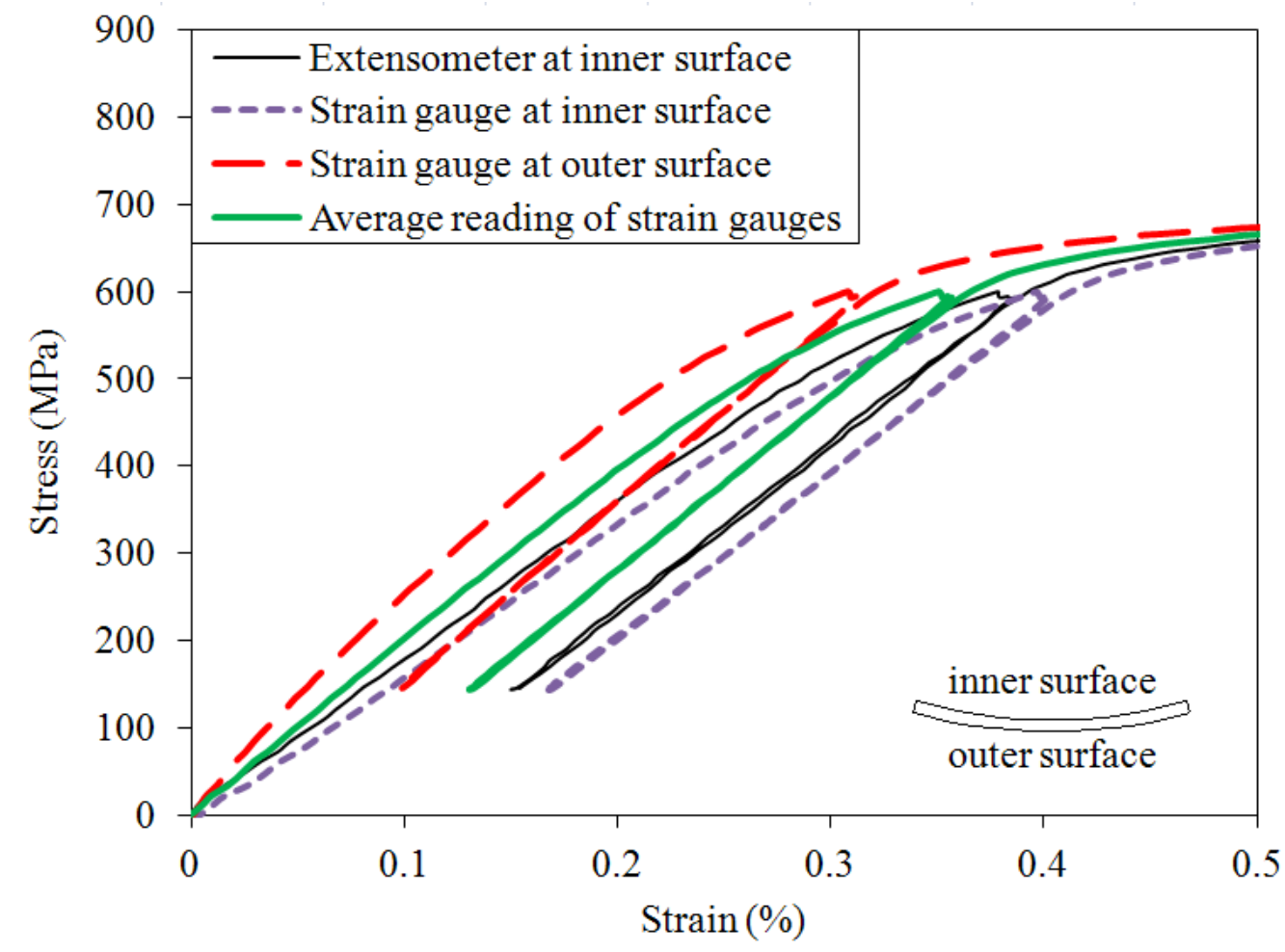

Fig 18: Different strain readings from the two sides of the coupon specimen LF-L1 due to initial curvature
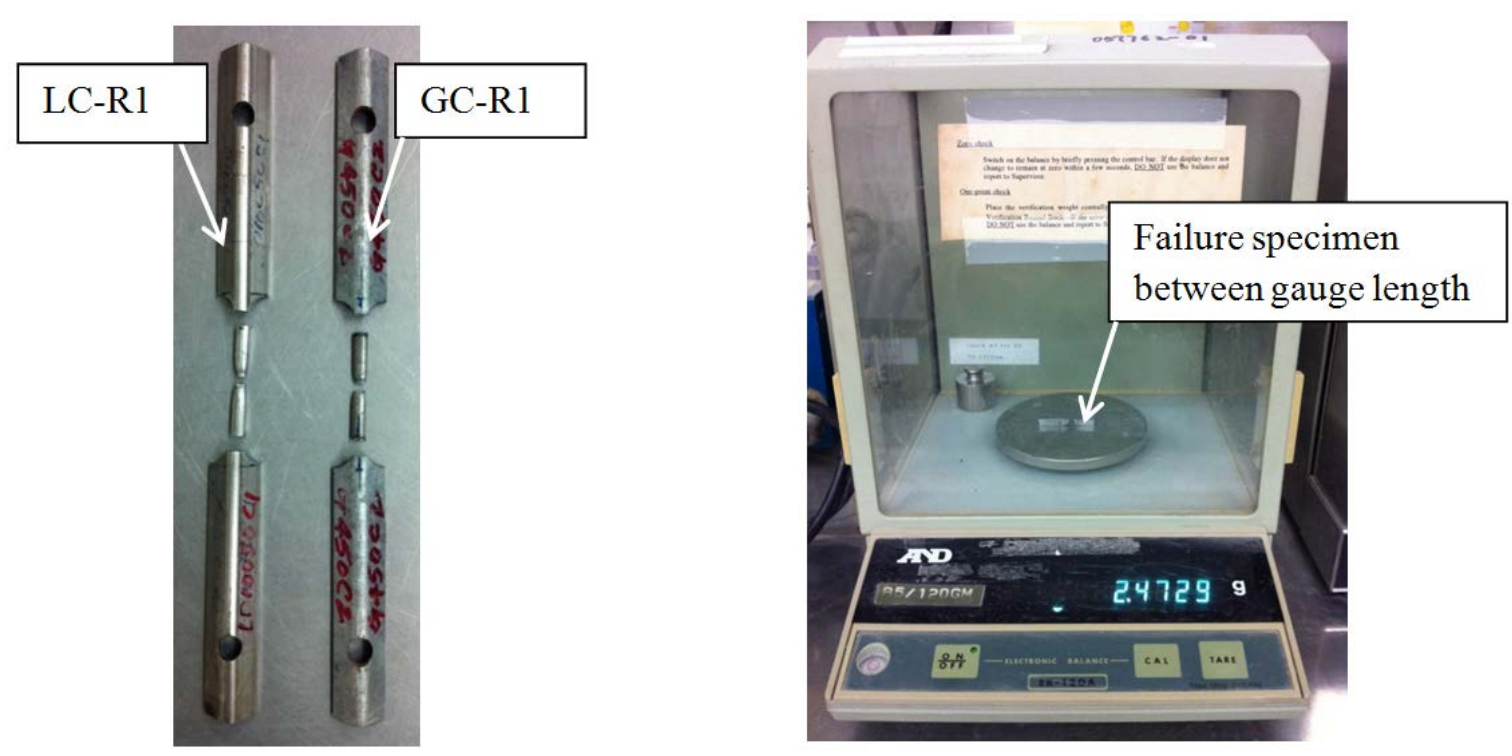

Fig 19: The weight and density method ( $1^{\text {st }}$ method) to determine the cross-sectional area of curved coupons 


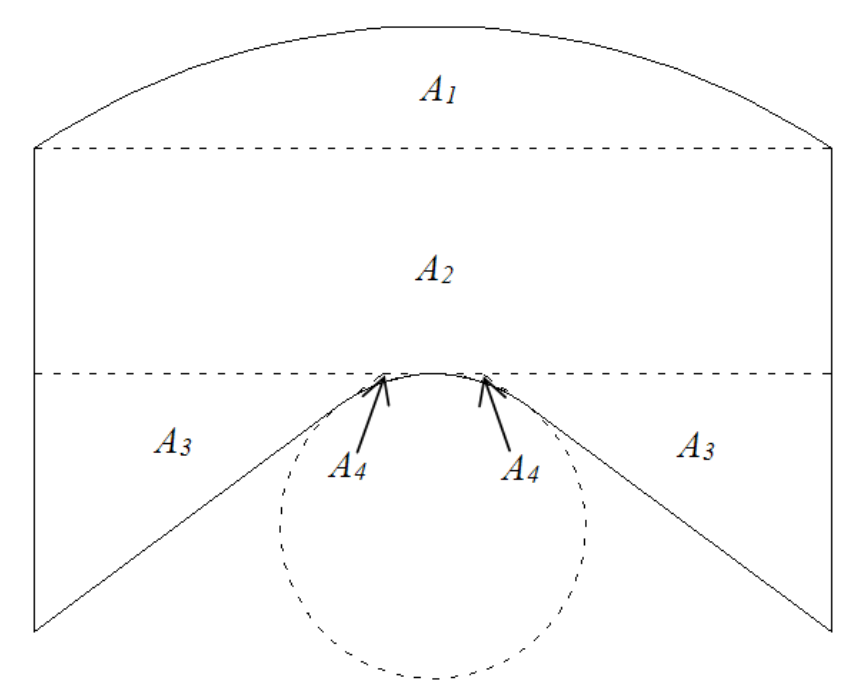

(a) Divided parts of the cross-sectional area for curved coupon specimens

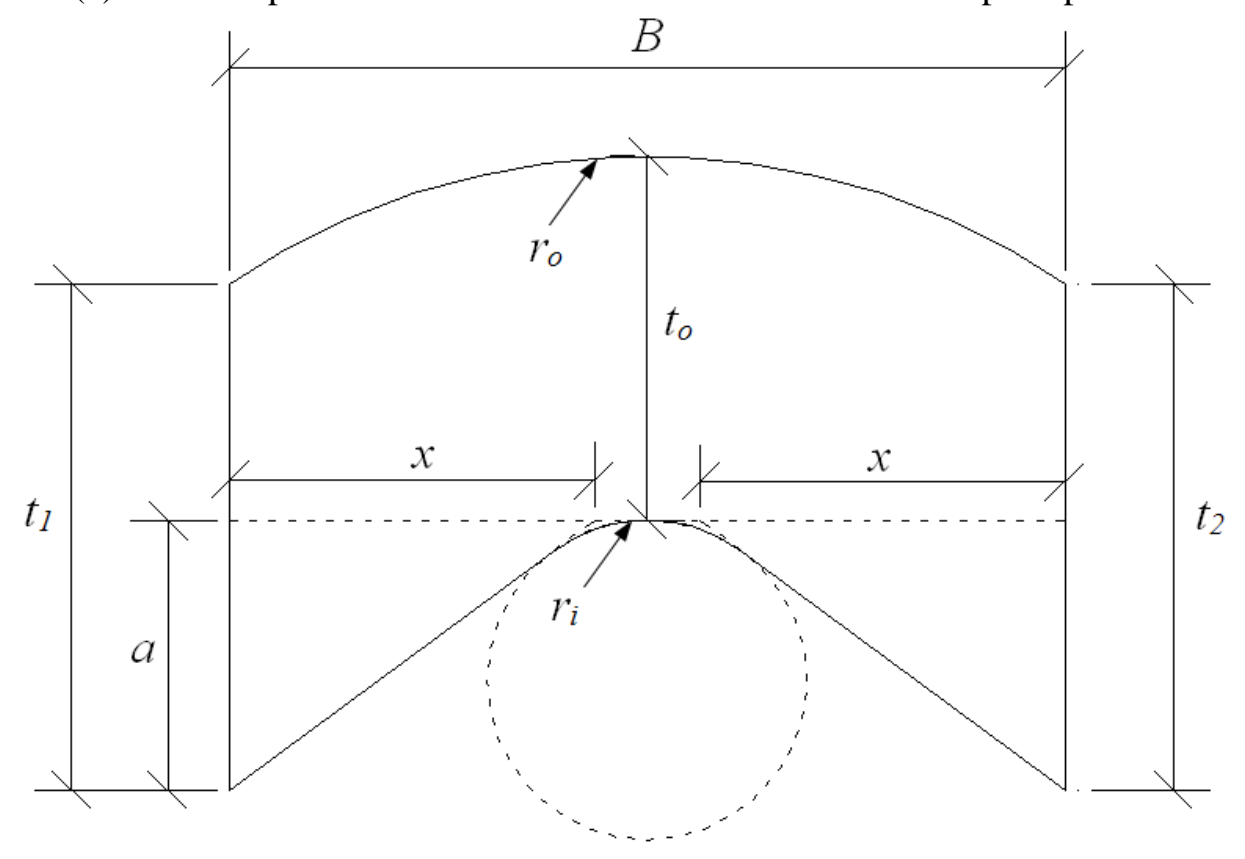

(b) Definition of symbols for cross-sectional dimensions

Fig 20: The $3^{\text {rd }}$ method for determining the cross-sectional area of curved coupons 


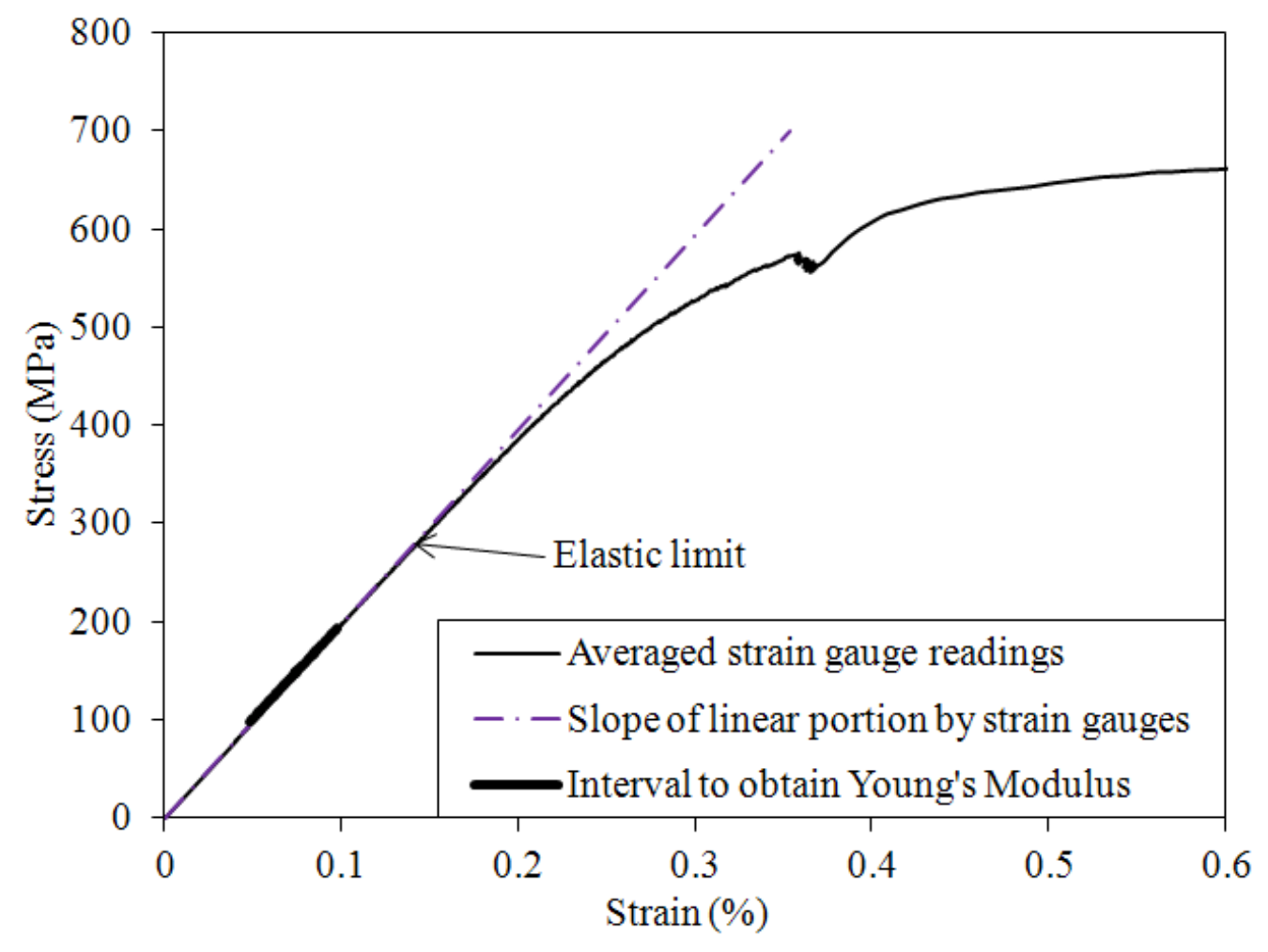

Fig 21: Determination of Young’s modulus and elastic limit

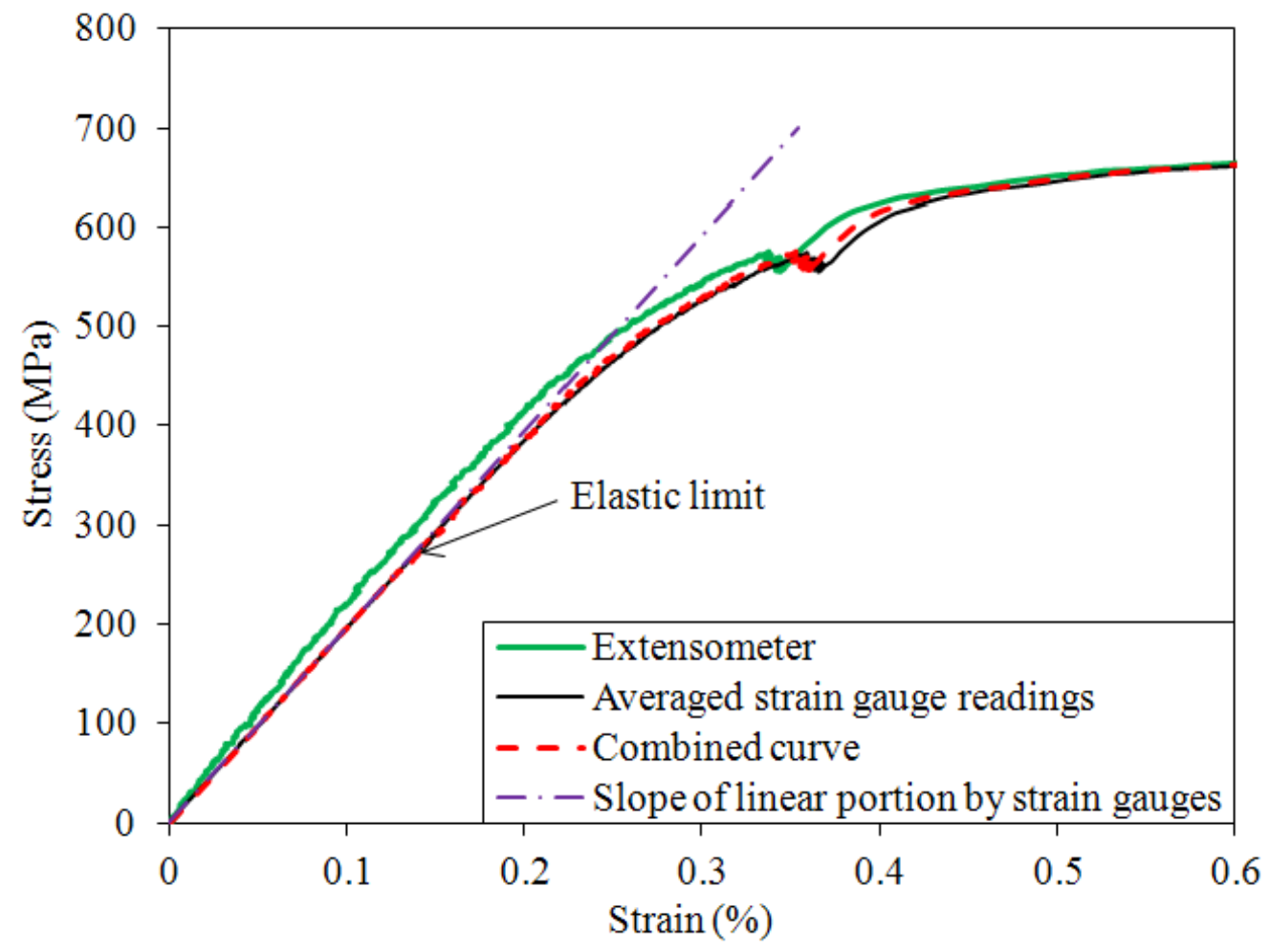

Fig 22: Combination of stress-strain curves obtained from strain gauge and extensometer readings 


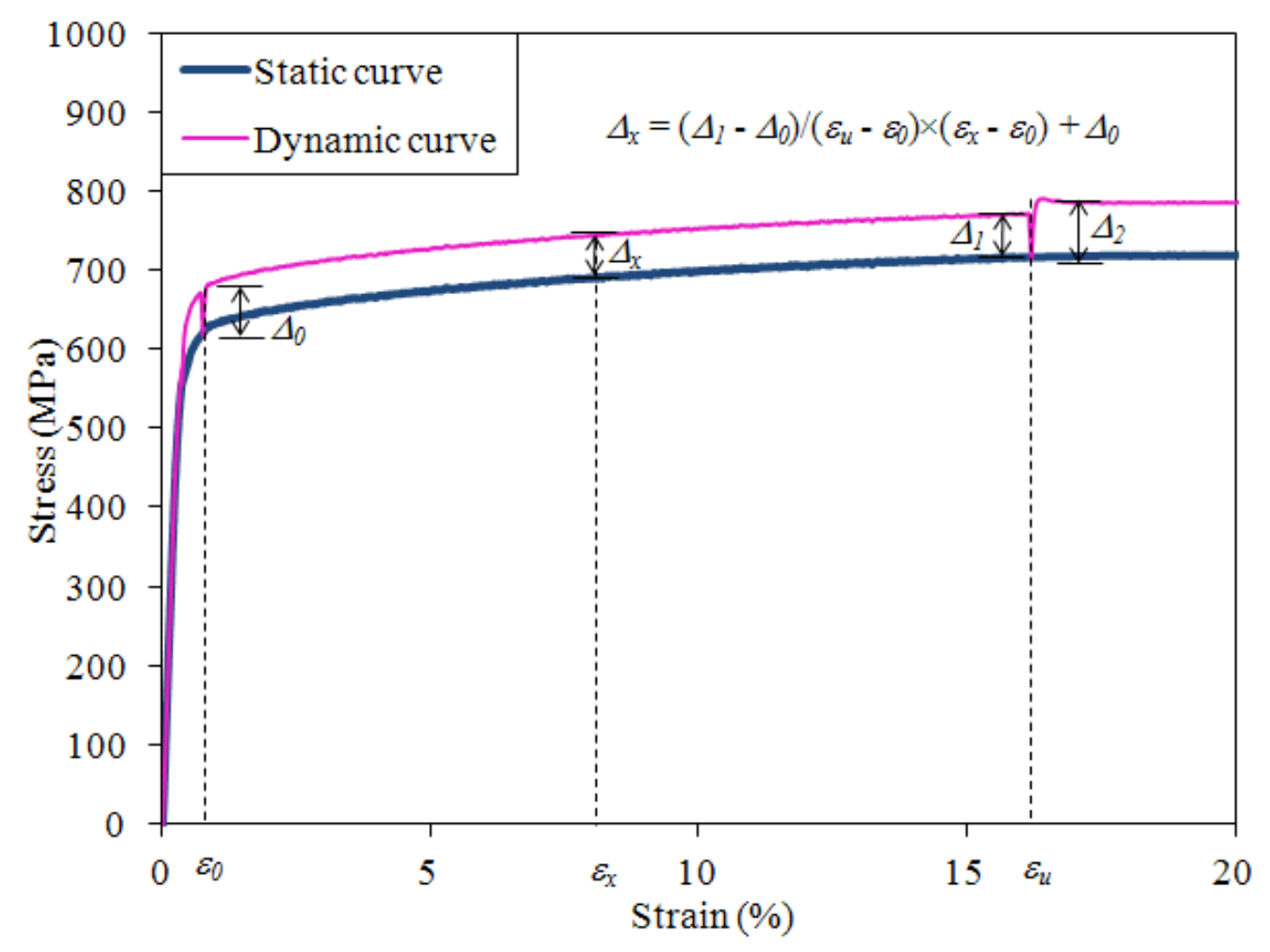

(a) Typical rounded static and dynamic stress-strain curves

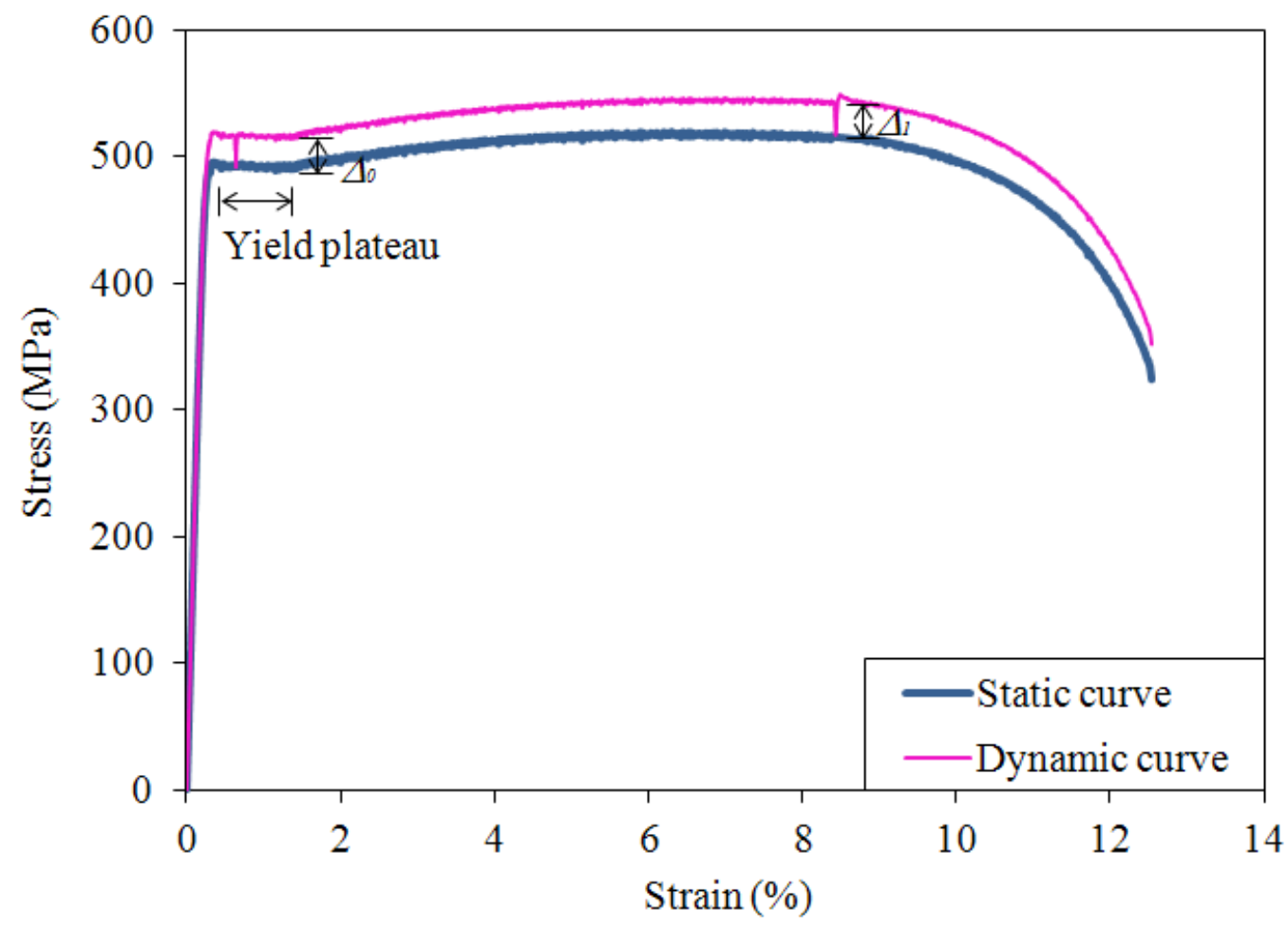

(b) Typical static and dynamic stress-strain curves with yield plateau

Fig 23: Reduction of stress from dynamic to static stress-strain curves 


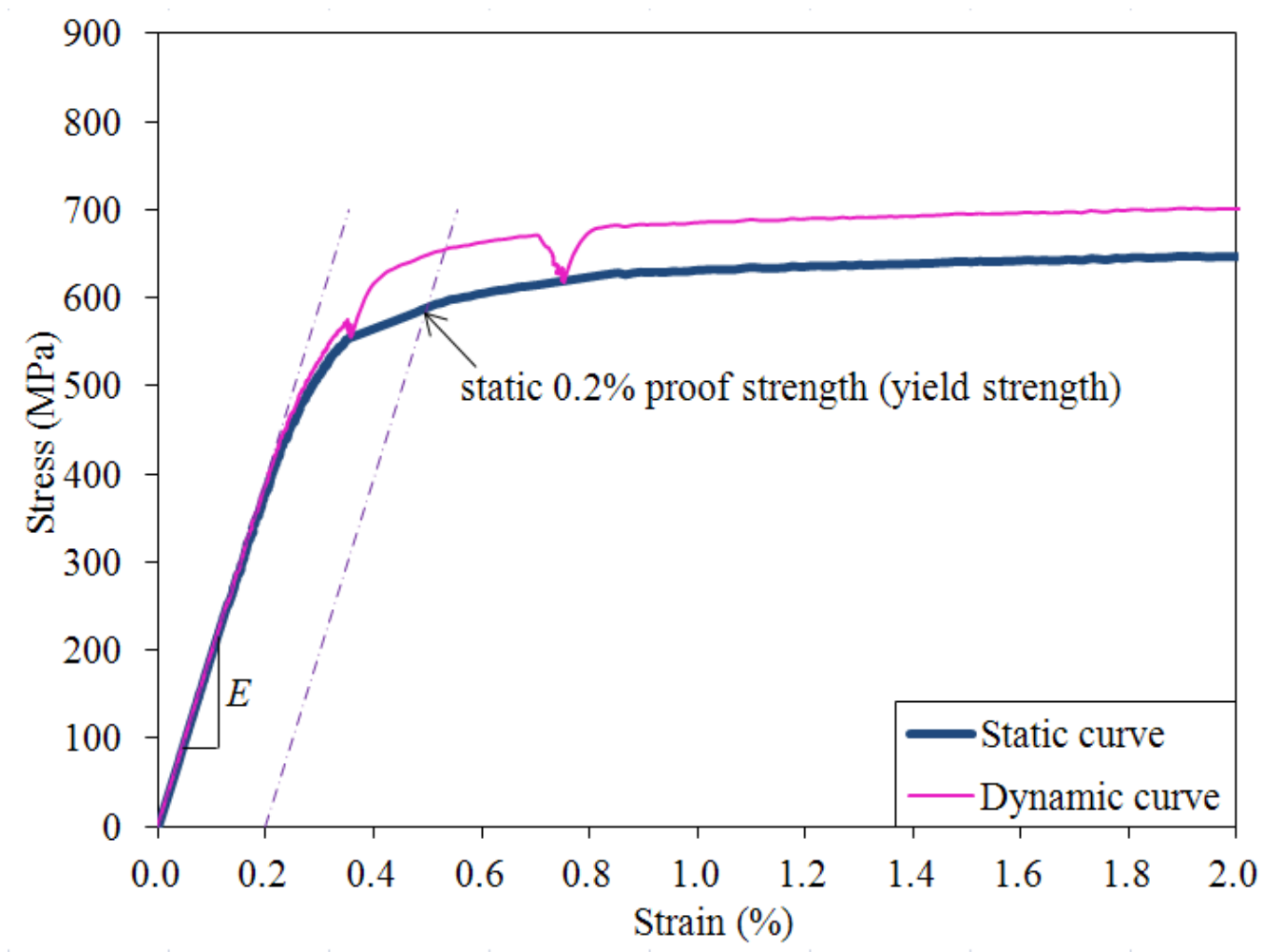

Fig 24: Determination of static 0.2\% proof strength (yield strength)

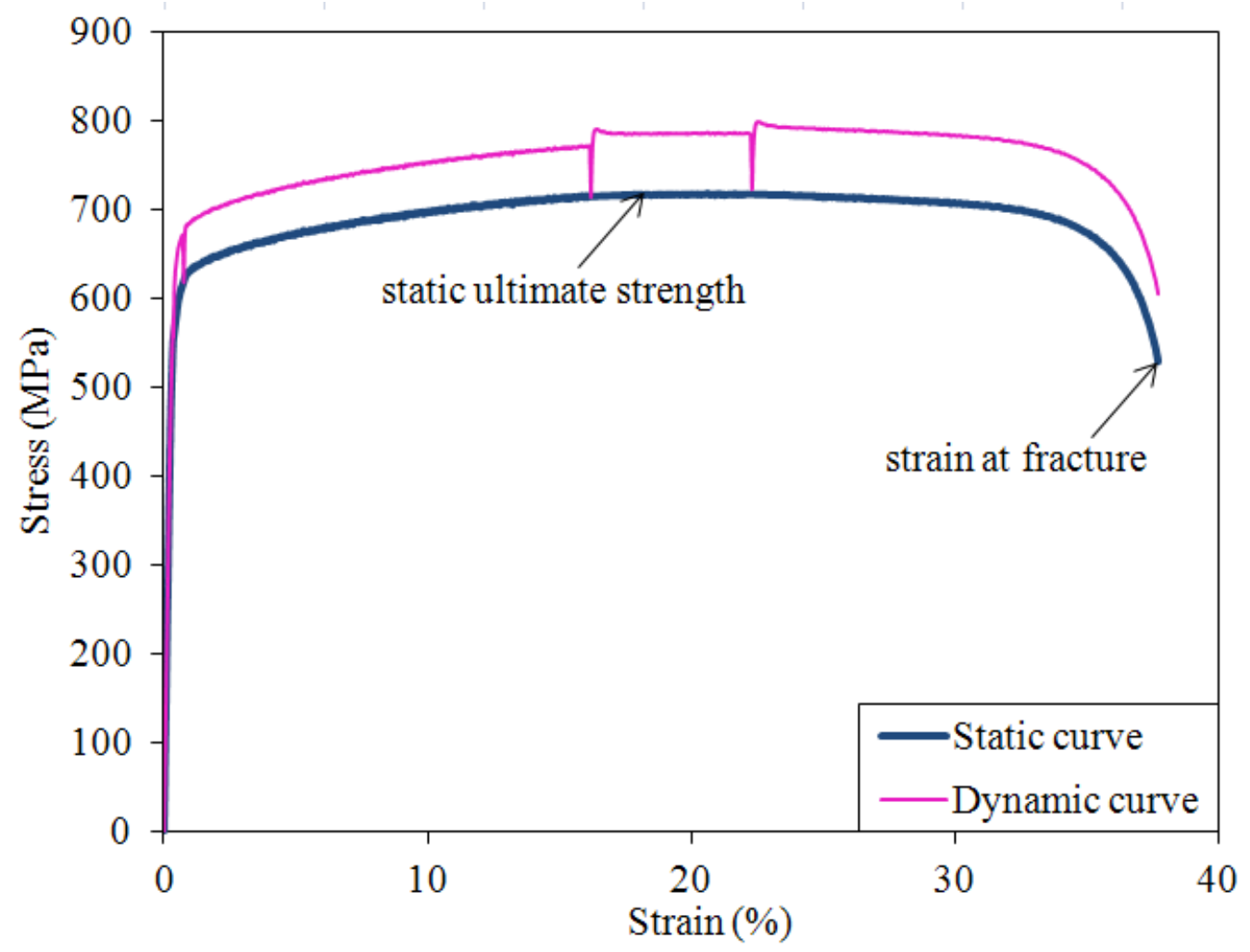

Fig 25: Determination of static ultimate strength and strain at fracture 